\title{
A Diagnosis of Two Blocking Events That Occurred Simultaneously in the Midlatitude Northern Hemisphere
}

\author{
ANTHONY R. LUPO \\ Department of Earth and Atmospheric Science, Purdue University, West Lafayette, Indiana
}

(Manuscript received 23 June 1996, in final form 20 November 1996)

\begin{abstract}
Using the Goddard Laboratory for Atmospheres Goddard Earth Observing System-1 analyses, the horizontal distribution of atmospheric forcing processes involved in the growth, maintenance, and decay of two Northern Hemisphere midlatitude blocking anticyclones that occurred simultaneously were examined, with the goal of determining whether there was a dynamic connection between the two cases. The complete form of the ZwackOkossi equation, which is a generalization of the Petterssen-Sutcliffe development equation, was used as the primary diagnostic tool. The basic analyses were partitioned into their planetary-scale and synoptic-scale components (noninteraction) 500-hPa height tendencies, as well as scale interaction 500-hPa height tendencies. Based on the results of this diagnosis, there was no dynamic connection between these blocking anticyclones. This result agrees with findings of other studies based on a statistical analysis of simultaneous blocking. These results also imply that blocking may be a local phenomenon.

The diagnostic results from these blocking events were, in many respects, similar to those of previous studies. However, some key differences were found. For example, it was found here that for both mode 2 blocking events, temperature advection was an important mechanism in block formation. Earlier results showed vorticity advection as the primary atmospheric forcing process in block formation for a mode 1 block. Also, the scalepartitioned results show that upstream cyclones contributed to block formation and intensification in these events directly through the synoptic-scale component, often with the support of the interaction component, of the total forcing. Earlier scale-partitioned results showed that the interaction component of the total forcing was most important in the formation of a mode 1 block.
\end{abstract}

\section{Introduction}

In the last three decades, there has been a renewed interest in the atmospheric phenomenon known as blocking. Many studies have been devoted to determining why blocks occur and their effects on operational forecasting. The occurrence of blocking anticyclones has been linked to orography and long-wave baroclinic processes (in particular, surface heating) (e.g., Charney and De Vore 1979; Dole 1986; Sperenza 1986), interactions between long waves (e.g., Blackmon et al. 1977; Austin 1980; Colucci et al. 1981; Lejenas and Madden 1992), or the resonant amplification of long waves forced by large-scale processes (e.g., Tung and Lindzen 1979a,b). Studies of blocking anticyclones have also shown that they are dynamically linked to the occurrence of midlatitude synoptic-scale cyclones, despite their differing spatial and temporal scales (e.g., KalnayRivas and Merkine 1981; Frederiksen 1982; Shutts 1983, 1986; Illari 1984; Colucci 1985, 1987; Trenberth

Corresponding author address: Dr. Anthony R. Lupo, Department of Earth and Atmospheric Science, ES-226, State University of New York at Albany, Albany, NY 12222.

E-mail: tlupo@atmos.albany.edu. and Mo 1985; Egger et al. 1986; Mullen 1987; Tracton 1990; Alberta et al. 1991; Mak 1991). In particular, the pioneering efforts of Kalnay-Rivas and Merkine (1981), Frederiksen (1982), and Shutts (1983) used simple models to demonstrate the importance of an ensemble of midlatitude transients in the formation/and or maintenance of blocking anticyclones. Since then, observational studies (including some of those referenced above), using a variety of methodologies, have shown the importance of vorticity transport by traveling synoptic-scale disturbances in maintaining a block against the tendency for the block to be advected away by the mean flow. However, relatively few [e.g., Konrad and Colucci 1988; Tsou and Smith 1990; Lupo and Smith 1995b (hereafter, LS95b)] have investigated the dynamic connection between the development of a particular surface cyclone event and block formation. Of course, it is also true that while a dynamical link may exist between intense cyclogenesis and block formation not every intense cyclone results in the formation of a blocking anticyclone (Konrad and Colucci 1988).

Among the recent studies of blocking anticyclones are a few that have investigated the possibility that blocking in one region may be linked to the occurrence or inhibition of blocking in another region of the North- 
ern or Southern Hemisphere. Lejenas and Okland (1983) examined this possibility for Northern Hemisphere blocking statistically and concluded that there is no relationship between blocking in the Atlantic and Pacific sectors. Trenberth and Mo (1985) briefly examined a case of "triple blocking" that occurred in the Southern Hemisphere during June and July 1985 . While they concluded that blocking was essentially a regional phenomenon, they noted that an amplified wavenumber 3 was prominent in Southern Hemisphere "multiple blocking," leaving open the possibility that large-scale forcing may play a role in multiple blocking occurrences.

The primary objective of this study is to determine if there is a dynamic connection between the simultaneous existence of two Northern Hemisphere anticyclones. The specific issue to be addressed here is whether or not there is a connection between the two events, that is, does blocking in one part of the Northern Hemisphere preferentially accompany, trigger, or suppress blocking in another part of the hemisphere, or is there no connection at all between their concurrent existence. The secondary objective is to compare and/or contrast the results of these diagnoses with those in the case study of LS95b, using the methodologies of the previous works in this series. In particular, the goal is to assess the relative importance of individual forcing mechanisms for these blocking events versus those of LS95b.

\section{Analyses}

The analyses used in this investigation were obtained from NASA/Goddard Laboratory for Atmospheres (GLA; Schubert et al. 1993). These fields include the upper-air parameters $u$ and $v$ (horizontal wind vector components in meters per second), $z$ (geopotential height in meters), $T$ (absolute temperature), $\mathrm{RH}$ (relative humidity), and $q$ (mixing ratio in grams per kilogram) on a $2.0^{\circ}$ latitude by $2.5^{\circ}$ longitude grid at 14 mandatory pressure levels from 1000 to $20 \mathrm{hPa}$ at 6-h intervals, which were then interpolated linearly in $\ln (p)$ to $50-\mathrm{hPa}$ isobaric levels. Also included are a variety of surface parameters; a complete list of these can be found in the paper mentioned above. At the time this study was performed, the assimilated dataset covered a $5-\mathrm{yr}$ period from 1 March 1985 through 28 February 1990. The GLA analysis scheme incorporates data from a variety of sources that include rawinsonde reports, satellite retrievals, cloud-motion winds, and aircraft, ship, and rocketsonde reports. The basic components of the assimilation system, model physics, and the parameterizations used in the Goddard Earth Observing System (GEOS) atmospheric general circulation model (AGCM) are described in more detail by Baker et al. (1987) and Schubert et al. (1993). Finally, subsets of these data are available upon request from the Goddard Distributed Active Archive Center (DAAC).

\section{Diagnostic methods and computational procedures}

The diagnoses of the individual blocking cases were accomplished using the Zwack-Okossi (Z-O) equation (Zwack and Okossi 1986) in its complete form (Lupo et al. 1992). The $\mathrm{Z}-\mathrm{O}$ equation is an expression that allows for the diagnosis of geostrophic vorticity tendency at a near-surface pressure level as forced by vertically integrated dynamic and thermodynamic forcing mechanisms. This equation is given by

$$
\begin{aligned}
& \left.\frac{\partial \zeta_{g}}{\partial t}\right|_{p_{l}}=\operatorname{PD} \int_{p_{t}}^{p_{l}}\left[-\mathbf{V} \cdot \boldsymbol{\nabla} \zeta_{a}-\omega \frac{\partial \zeta_{a}}{\partial p}+\zeta_{a} \frac{\partial \omega}{\partial p}-\mathbf{k} \cdot\left(\boldsymbol{\nabla} \omega \times \frac{\partial \mathbf{V}}{\partial p}\right)+\mathbf{k} \cdot(\boldsymbol{\nabla} \times \mathbf{F})-\frac{\partial \zeta_{\mathrm{ag}}}{\partial t}\right] d p \\
& \begin{array}{llllll}
\text { (a) } & \text { (b) } & \text { (c) } & \text { (d) } & \text { (e) } & \text { (f) }
\end{array} \\
& \text { vadv vvte dive tilt fric ageo } \\
& -\frac{\mathrm{PD}) R}{f} \int_{p_{t}}^{p_{l}}\left[\int_{p}^{p_{l}} \nabla^{2}\left(-\mathbf{V} \cdot \boldsymbol{\nabla} T+\frac{\dot{Q}}{c_{p}}+S \omega\right) \frac{d p}{p}\right] d p, \\
& \text { (g) (h) (i) } \\
& \text { tadv diab adia }
\end{aligned}
$$

where $\zeta_{g}$ is the geostrophic relative vorticity and $p_{l}$ represents the near-surface level (the first 50-hPa pressure level above the earth's surface at any grid point). In (1), V is the horizontal wind vector, $\dot{Q}$ the diabatic heating, $S$ the static stability parameter $(-T / \theta \partial \theta / \partial p), \omega$ the vertical motion $(d p / d t), \mathbf{F}$ is the frictional force, $\zeta_{a}$ the absolute vorticity, $\zeta_{\text {ag }}$ the ageostrophic vorticity, and $\boldsymbol{\nabla}$ the del operator on an isobaric surface; $R, c_{p}, T, f$, and $\theta$ are the gas constant for dry air, the specific heat at a constant pressure, absolute temperature, Coriolis force, and the potential temperature, respectively. Also, PD is $\left(p_{l}-p_{t}\right)^{-1}$, where $p_{t}$ is the pressure at some sufficiently 
high pressure level chosen to encompass most of the atmospheric mass, chosen to be $30 \mathrm{hPa}$ in this study. Forcing mechanisms (a)-(f) on the right-hand side of (1), which are the dynamic forcing mechanisms obtained from the vorticity equation, are, respectively, horizontal vorticity advection, vertical vorticity advection, divergence, vorticity tilting, frictional forcing, and the ageostrophic vorticity tendency. The remaining terms $[(\mathrm{g}),(\mathrm{h})$, and (i)], which are the thermal forcing mechanisms obtained from the first law of thermodynamics, are, respectively, the horizontal temperature advection, diabatic processes, and adiabatic temperature change. A physical description of the dynamic and thermodynamic forcing mechanisms can be found in Zwack and Okossi (1986), Rausch and Smith (1996), or Rolfson and Smith (1996).

To use the Z-O methodology for diagnoses at pressure levels aloft, it is necessary to express the diagnostic quantity as a geostrophic vorticity tendency equation that includes the near-surface geostrophic vorticity tendency as a forcing process. This is accomplished by solving the geostrophic vorticity tendency equation [see (Eq.) 3 in Lupo et al. 1992] for some specified level (e.g., $p_{i}=500$ $\mathrm{hPa}$ ) as was done in LS95b. The result is a $\mathrm{Z}-\mathrm{O}$ equation for pressure levels aloft [Eq. (1) in LS95b]:

$$
\left.\frac{\partial \zeta_{g}}{\partial t}\right|_{p_{i}}=\left.\frac{\partial \zeta_{g}}{\partial t}\right|_{p_{l}}+\frac{R}{f} \int_{p_{i}}^{p_{l}} \nabla^{2}\left(-\mathbf{V} \cdot \nabla T+\frac{\dot{Q}}{c_{p}}+S \omega\right) \frac{d p}{p},
$$

where (1) is substituted for the near-surface geostrophic vorticity tendency $\partial \zeta_{g} / \partial t \mid p_{l}$. In this study, both (1) and (2) were relaxed to produce height tendencies at $p_{l}$ and $p_{i}$. These tendencies were then filtered to remove all information below $5 \Delta x$, thus removing subsynoptic-scale signal and noise present due to data, model, and computational errors. The filtering process is described below.

In (1) and (2), $\omega$ was calculated using a complete form of the omega equation similar to that of Krishnamurti (1968):

$$
\begin{aligned}
\nabla^{2} \sigma \omega+f \zeta_{a} \frac{\partial^{2} \omega}{\partial p^{2}}= & f \frac{\partial}{\partial p}\left(\mathbf{V} \cdot \nabla \zeta_{a}-\mathbf{k} \cdot \boldsymbol{\nabla} \times \mathbf{F}+\frac{\partial \mathbf{V}}{\partial p} \times \nabla \omega\right) \\
& +f \omega \frac{\partial^{2} \zeta}{\partial p^{2}}+\frac{R}{p} \nabla^{2}\left(\mathbf{V} \cdot \nabla T-\frac{\dot{Q}}{C_{p}}\right)
\end{aligned}
$$

where $\sigma$ is the static stability parameter $\sigma=(-R T / p \theta) /$ $(d \theta / d p)$. This form of the omega equation was chosen because of its compatibility with (1) and (2); that is, each of the forcing processes that appear in (1) and (2) has a complement in (3).

In (1), (2), and (3) the frictional force was restricted to the boundary layer and was calculated using the Krishnamurti (1968) algorithm. Diabatic heating included convective and stable latent heat release calculated using the Kuo (1974) convective parameterization and a stable parameterization, both described by Fosdick and Smith (1991) and Lupo et al. (1992); boundary layer sensible heating obtained from the Krishnamurti (1968) parameterization as applied by Lupo et al. (1992); and a longwave radiation parameterization (Sasamori 1968) that assumes randomly overlapped clouds (Harshvardhan et al. 1987). The surface sensible heat flux required in the boundary layer sensible heating calculations was provided by the GLA analyses described in section 2 . The ageostrophic vorticity tendency was calculated as the centered 6-h finite difference of the ageostrophic winds estimated using the approach of Trenberth and Chen (1988). All horizontal (vertical) derivatives were calculated using fourth- (second-) order finite differencing. Vertical integrals were calculated using the trapezoidal rule, and all relaxation was accomplished using sequential overrelaxation (SOR) (Haltiner and Williams 1980, 157-164) with all vertical and lateral boundary conditions fixed at zero. All the computations described here were carried out over the entire Northern Hemisphere to reduce the influence of the boundaries in the central region of the grid. Smaller regions were chosen for examining the $\mathrm{Z}-\mathrm{O}$ computational height tendencies. These domains, of $40^{\circ}$ latitude by $60^{\circ}$ longitude centered as closely as possible to the block center, were chosen to encompass the blocking anticyclone and the immediate vicinity in the upstream and downstream directions.

In accomplishing some of the objectives of this work, it was necessary to partition the analyses into their "planetary-scale" and "synoptic-scale" components. The scale partitioning of these fields was accomplished using a Shapiro (1970) filter. This procedure is described in more detail by LS95b; thus, only a brief summary will be given here. The filtered analyses, which retained $2 \%, 44 \%$, and $80 \%$ of the signal at wavelengths of 3000,4500 , and 6000 $\mathrm{km}$, respectively, were identified as the planetary-scale $(P)$ component, while the part that was filtered out (the difference between the total and filtered component) was the synoptic-scale $(S)$ component. Also, as previously noted, a final filtering of the height tendencies was done to remove small-scale $(<1000 \mathrm{~km})$ noise without significantly degrading the synoptic-scale component. This was accomplished using a fourth-order, two-dimensional Shapiro (1970) filter applied to all height tendencies.

The filtered analyses were used in a partitioned form of the $\mathrm{Z}-\mathrm{O}$ equation derived by substituting for each variable $X$,

$$
X=\bar{X}+X^{\prime}
$$

where $\bar{X}\left(X^{\prime}\right)$ represents the planetary- (synoptic-) scale component. Using partitioned variables in (1) yields a $\mathrm{Z}-\mathrm{O}$ equation of the form

$$
\left.\frac{\partial \zeta_{g}}{\partial t}\right|_{p_{i}}=P+S+I,
$$

where $P, S$, and $I$ represent the planetary-scale, synopticscale, and scale-interaction components, respectively, of the forcing processes on the right-hand side of (1) or (2). An example of the partitioning, as applied to term (a) on the right-hand side of (1) or (2), is 


$$
\left.\left.\frac{\partial \zeta_{g}}{\partial t}\right|_{p_{i}}\right|_{\mathrm{vadv}}=\left.\left.\frac{\partial \zeta_{g}}{\partial t}\right|_{p_{l}}\right|_{\mathrm{vadv}}=\mathrm{PD} \int_{p_{t}}^{p_{l}} \begin{gathered}
\left(-\overline{\mathbf{V}} \cdot \nabla \bar{\zeta}_{a}-\mathbf{V}^{\prime} \cdot \boldsymbol{\nabla} \zeta_{a}^{\prime}-\overline{\mathbf{V}} \cdot \boldsymbol{\nabla} \zeta_{a}^{\prime}-\mathbf{V}^{\prime} \cdot \boldsymbol{\nabla} \bar{\zeta}_{a}\right) d p \\
P
\end{gathered}
$$

where I1 is the advection of synoptic-scale vorticity by the planetary-scale wind, I2 is the advection of planetary-scale vorticity by the synoptic-scale wind, and I1 + I2 equals the total interaction (I). Finally, the $P$ and $S$ height tendencies are forced by processes occurring within each spatial domain, that is, large-scale waves $(P)$ or synoptic-scale cyclones $(S)$, whereas $I$ height tendencies suggest a transfer of properties among spatial domains (see Tracton 1990).

Finally, to identify the flow regime in which the blocking events occurred, the wave amplitude index (WI) was used (Hansen 1986; Sutera 1986). This characteristic of the planetary-scale flow was examined to determine what differences, if any, there are in block formation and maintenance for atmospheres in low (mode 1, e.g., the blocking event in LS95b) and high (mode 2, e.g., the blocking events studied here) amplitude planetary-scale flow regimes. The wave amplitude index is expressed as

$$
\mathrm{WI}=\left(\sum_{m=2}^{4} 2 Z_{m}^{2}\right)^{1 / 2},
$$

where $Z_{m}$ represents the Fourier coefficients for zonal wavenumber $m ; Z_{m}$ was calculated using $500-\mathrm{hPa}$ heights averaged with respect to latitude from $22.5^{\circ}$ to $77.5^{\circ} \mathrm{N}$ and then Fourier decomposed in the zonal direction. Plotting these values on a histogram yields a probability density distribution that is clearly bimodal, with one peak corresponding to a "low amplitude" (mode 1) flow regime, and the other to a "high amplitude" (mode 2) flow regime (Hansen 1986; Sutera 1986). The set of twice-daily WI values derived from the European Centre for Medium-Range Weather Forecasts (ECMWF) analyses was graciously provided by Dr. A. Hansen.

\section{Synoptic discussion}

\section{a. The Atlantic blocking event}

The two simultaneously occurring blocking anticyclones selected for this study were drawn from the climatological study of Lupo and Smith (1995a; hereafter LS95a). Figure 1a is a graph of the $500-\mathrm{hPa}$ central or maximum height values spanning the preblock $500-\mathrm{hPa}$ ridge and the block that occurred over the North Atlantic in November 1985. Significant dates and periods within the blocking anticyclone's life cycle are labeled on the $x$ axis or defined inside the figure. The procedures for choosing the central or maximum height values, time of block onset and termination, and other blocking characteristics are specified in LS95a.

Block development was defined as the period bounded by the commencement of the 24-h period of most rapid deepening by the precursor surface cyclone and block onset. This period for the Atlantic case is represented by 0000 UTC 13 November 1985 (Fig. 2a). At this time, a quasi-stationary 500-hPa long-wave ridge (trough) was located over the eastern Atlantic and western Europe, including the North Sea (over the North Atlantic). An amplifying short wave was also evident just southeast of Greenland and over Iceland. The associated surface low (number 1 in Fig. 2a) was located at $64^{\circ} \mathrm{N}, 25^{\circ} \mathrm{W}$ and had a central pressure of $984 \mathrm{hPa}$, and the importance of precursor surface cyclogenesis to
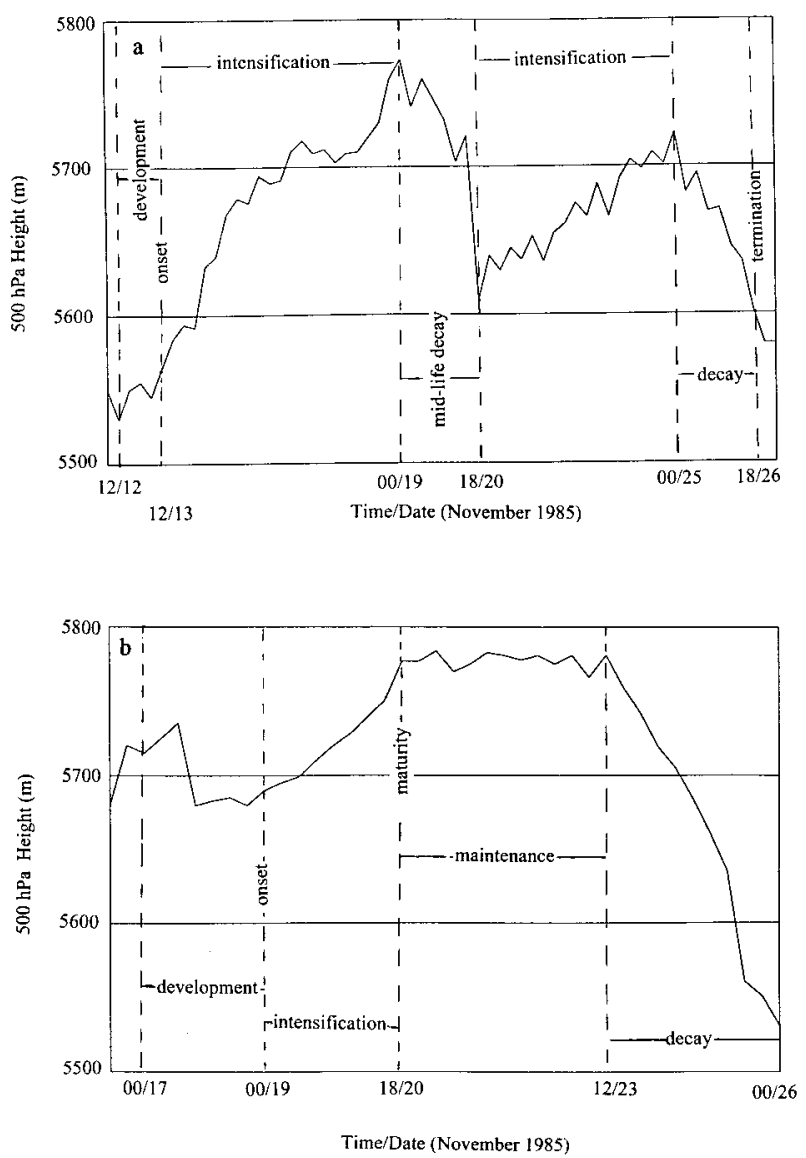

FIG. 1. Plot of the 500-hPa maximum or central height values (m) blocking anticyclone versus time for the (a) Atlantic and (b) Pacific blocking event. Important periods of time within the block's life cycle are separated by vertical dashed lines. 
$500 \mathrm{hPa}$ Heights (m) 0000 UTC 13 November 85

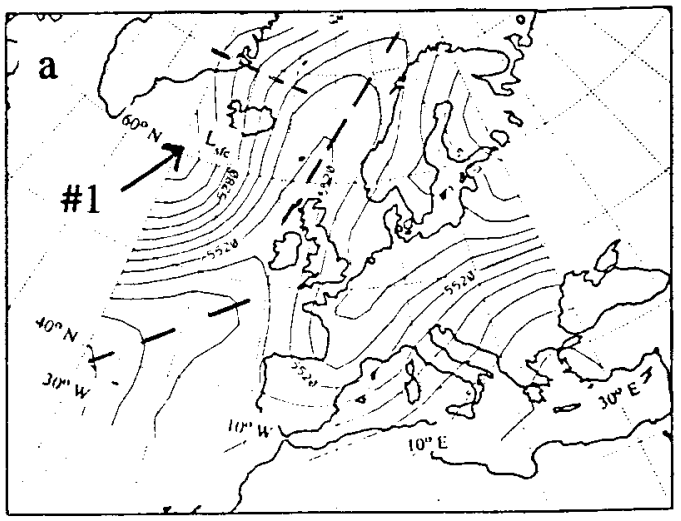

$500 \mathrm{hPa}$ Heights (m) 1200 UTC 13 November 85

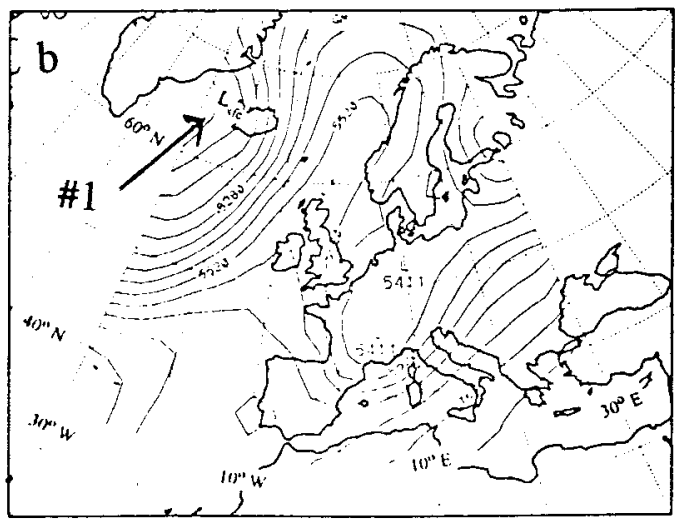

500 hPa Heights (m) 0600 UTC 16 November 85

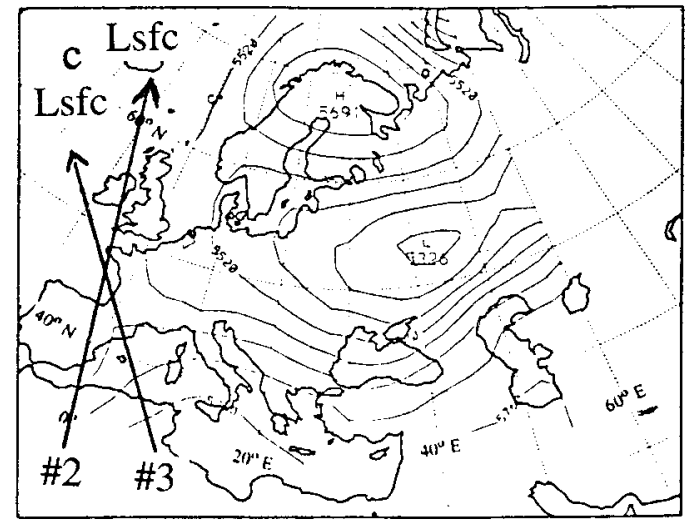

$500 \mathrm{hPa}$ Heights (m) 0000 UTC 19 November 85

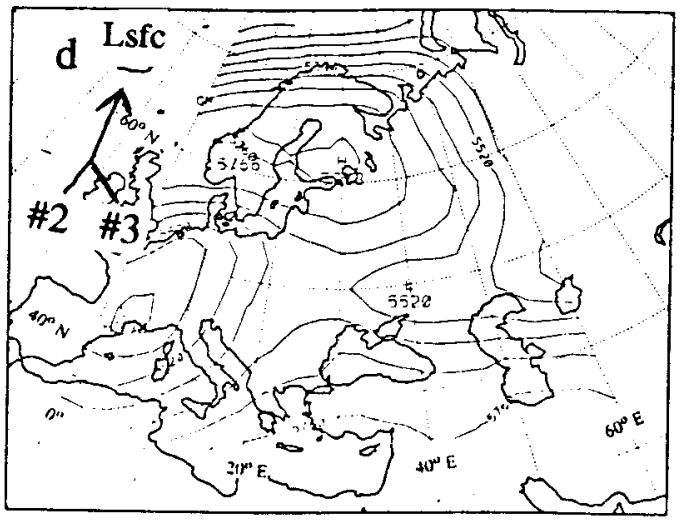

$500 \mathrm{hPa}$ Heights $(\mathrm{m}) 0000$ UTC 23 November 85

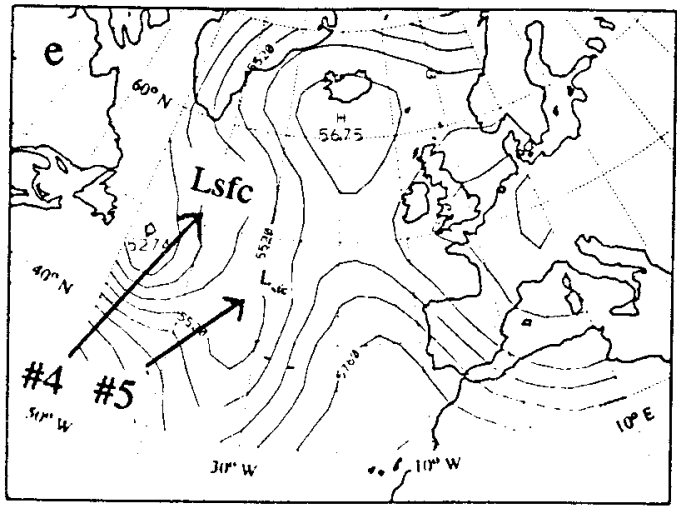

$500 \mathrm{hPa}$ Heights (m)0000 UTC 26 November 85

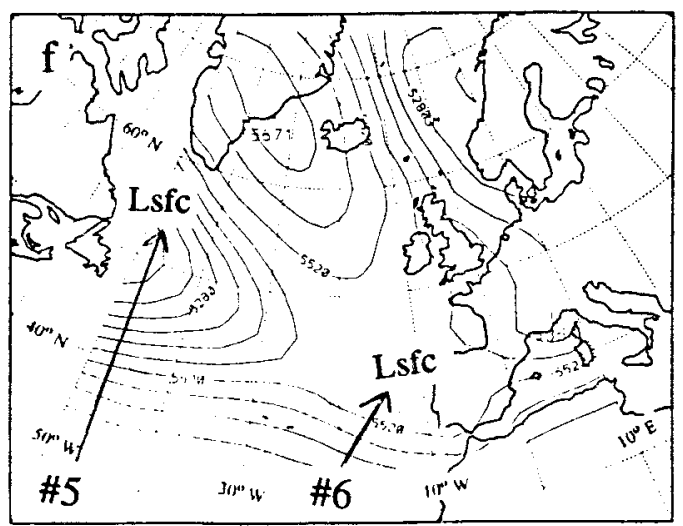

FIG. 2. Regional 500-hPa height (m) maps for (a) 0000 UTC 13 November, (b) 1200 UTC 13 November, (c) 0600 UTC 16 November, (d) 0000 UTC 19 November, (e) 0000 UTC 23 November, and (f) 0000 UTC 26 November 1985. The contour intervals are $60 \mathrm{~m}$. The surface cyclones are denoted by an Lsfe on the height maps and numbered according to the discussion.

block development and the associated kinematic and dynamic analysis is presented in more detail by Tsou and Smith (1990) and LS95b.

Block onset occurred at 1200 UTC 13 November 1985 (Fig. 2b) and was centered on $64^{\circ} \mathrm{N}, 5^{\circ} \mathrm{E}$ at 500
hPa. After this time, the block intensified (Fig. 1a) during the next $126 \mathrm{~h}$ and slowly migrated eastward over the North Sea and Scandinavia, reaching Finland $\left(68^{\circ} \mathrm{N}\right.$, $30^{\circ} \mathrm{E}$ ) by 1800 UTC 15 November and then remaining stationary for the balance of the intensification period. 
The associated surface cyclone $\left(66^{\circ} \mathrm{N}, 27.5^{\circ} \mathrm{W}\right)$ had reached its lowest central pressure of $973 \mathrm{hPa}$ at 1200 UTC 13 November and later filled rapidly as it moved toward Greenland. At 0600 UTC 14 November, a second cyclone developed south of Greenland $\left(56^{\circ} \mathrm{N}, 45^{\circ} \mathrm{W}\right)$ with an initial central pressure of around $990 \mathrm{hPa}$. By 0600 UTC 16 November (Fig. 2c), this cyclone (number $2 ; 62^{\circ} \mathrm{N}, 40^{\circ} \mathrm{W}$ ) had attained a minimum central pressure of $960 \mathrm{hPa}$ and was following a track similar to that of its predecessor. A third surface cyclone developed rapidly after 1800 UTC 16 November to the southeast and east of the second cyclone and could be associated with the more rapid intensification of the block between 0000 UTC 18 November and 0000 UTC 19 November (Fig. 1a). By 0000 UTC 19 November, both cyclones had moved northeastward, merged, and were filling to the northwest of the block (Fig. 2d).

The peak $500-\mathrm{hPa}$ central height value for this case was attained at 0000 UTC 19 November 1985. Following this time, the central height values decreased over a 48-h period and the block moved westward so that by 0600 UTC 22 November this case was centered at $58^{\circ} \mathrm{N}$, $17.5^{\circ} \mathrm{W}$. During that migration, the block experienced a second intensification that began at 1800 UTC 20 November (Fig. 1a). At 0000 UTC 23 November, the block was located at $62^{\circ} \mathrm{N}, 20^{\circ} \mathrm{W}$ (Fig. 2e), and this map time represents the second period of intensification that culminated with a secondary central height maximum on 0000 UTC 25 November. Note also, in Fig. 2e, there was another surface cyclone (number $5 ; 46^{\circ} \mathrm{N}, 30^{\circ} \mathrm{W}$ ) located over the central North Atlantic with a central pressure of $995 \mathrm{hPa}$. This cyclone was at the start of a 24-h period of rapid development, during which the cyclone moved northwestward to $54^{\circ} \mathrm{N}, 42.5^{\circ} \mathrm{W}$ and attained a minimum central pressure of $982 \mathrm{hPa}$. A fourth surface cyclone had developed rapidly over northeast Quebec from 0000 UTC 21 November and filled rapidly following 0000 UTC 22 November. Additionally, a sixth surface cyclone developed to the southeast of the fifth from 1800 UTC 23 November to 1200 UTC 24 November. The latter series of cyclones were associated with the slower, more steady strengthening of the block during this second intensification period (Fig. 1a).

Decay of this block began after 0000 UTC 25 November and is represented by 0000 UTC 26 November (Fig. 2f). At 0000 UTC 26 November, the center was located at $66^{\circ} \mathrm{N}, 35^{\circ} \mathrm{W}$. Unlike the case examined in LS95b, there was a distinct period of falling central height values (Fig. 1a), no southward migration of the block center, and no upstream surface cyclone development taking place. Finally, this block slowly lost its identity until it failed to meet the blocking criteria of LS95a after 1800 UTC 26 November.

\section{b. The Pacific blocking event}

This case occurred over the eastern Pacific Ocean and Alaskan region and onset was 5.5 days after the onset of the Atlantic block. Figure 1b represents the central height values of the preblocking ridge and this blocking event throughout its life cycle. The development period for this case is represented in Fig. 3a by 0000 UTC 18 November 1985. By this time, a surface cyclone (number $1 ; 48^{\circ} \mathrm{N}, 172.5^{\circ} \mathrm{W}$ ) had deepened explosively and attained a central pressure of $979 \mathrm{hPa}$. The $500-\mathrm{hPa}$ ridge (Fig. 3a), whose axis was oriented southeastnorthwest across the Gulf of Alaska and western Alaska, had remained stationary and amplified toward the northwest during this period. However, unlike the Atlantic block or the case study of Tsou and Smith (1990), there was little visual evidence of an amplifying 500-hPa short-wave ridge during the development of this case.

Block onset (Fig. 3b) occurred at 0000 UTC 19 November 1985 over western Alaska. This block, unlike its Atlantic counterpart, would remain quasi-stationary over its entire life cycle. The associated surface cyclone (number 1) had remained stationary over the previous $24 \mathrm{~h}$ and had begun to fill. In the 6 and $12 \mathrm{~h}$ that followed this time, respectively, two additional surface cyclones appeared to the southeast and west $\left(32^{\circ} \mathrm{N}, 162.5^{\circ} \mathrm{W}\right.$ and $50^{\circ} \mathrm{N}, 165^{\circ} \mathrm{E}$ ), respectively, of the first cyclone. After 0000 UTC 19 November, the block intensified, as demonstrated by the increasing central height values (Fig. 1b). The block reached maturity by 1800 UTC 20 November, after which time the central height values were nearly constant until 1200 UTC 23 November (Fig. 1b). The mature blocking anticyclone was over western Alaska at 0000 UTC 22 November (Fig. 3c) when the block attained its maximum central height value. In the $72 \mathrm{~h}$ between onset and 0000 UTC 22 November, the second two surface cyclones (numbers 2 and 3 in Fig. 3c) mentioned above developed rapidly. By 0000 UTC 22 November, the second (third) cyclone (Fig. 3c) had moved northwestward (northward) to $50^{\circ} \mathrm{N}, 175^{\circ} \mathrm{W}$ $\left(54^{\circ} \mathrm{N}, 167.5^{\circ} \mathrm{E}\right)$ and was filling.

The decay period, represented here by 1800 UTC 24 November (Fig. 3d), for this block began after 1200 UTC 23 November and was marked by a 60 -h period of falling central height values. In Fig. 3d, the block center was located over the Gulf of Alaska and, like the LS95b case, was characterized by both a slow southward migration and an association with another rapidly developing surface cyclone (number 4, Fig. 3d) located within an advancing upstream 500-hPa trough. Following 1800 UTC 24 November, the block center continued to migrate southward, and the block slowly lost its identity until it no longer met the blocking criteria of LS95a after 0000 UTC 26 November.

\section{Diagnostic results}

For brevity, the ensuing map-based discussions will focus on the results for map times representative of the block development, intensification, maintenance, and decay periods at the 500-hPa level, even though all 6-h map times for each blocking anticyclone lifetime at 500 
$500 \mathrm{hPa}$ Heights (m) 0000 UTC 18 November 85

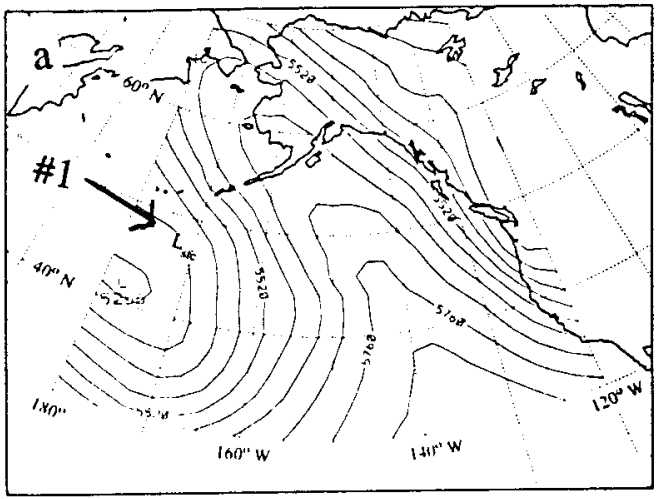

$500 \mathrm{hPa}$ Heights (m) $\quad 0000$ UTC 19 November 85

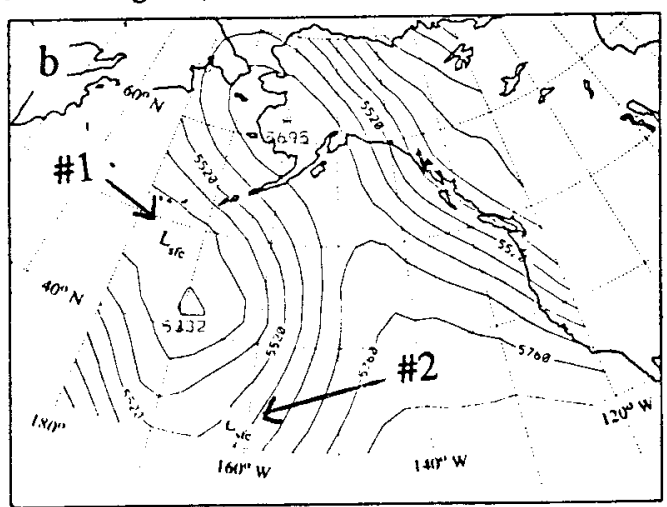

$500 \mathrm{hPa}$ Heights (m) 0000 UTC 22 November 85.

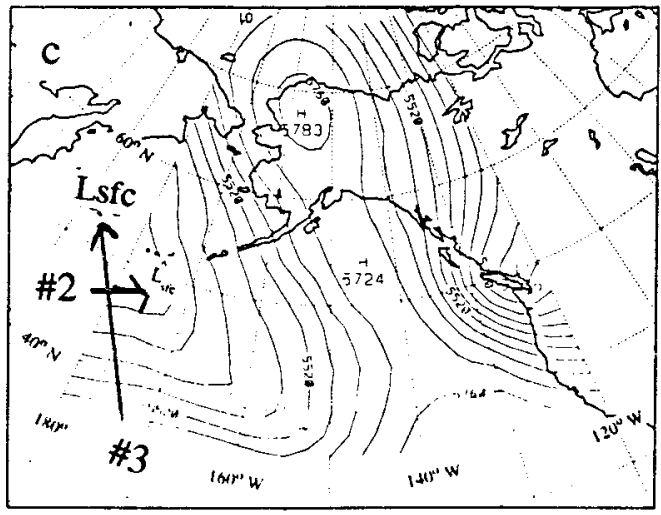

$500 \mathrm{hPa}$ Heights (m) 1800 UTC 24 November 85.

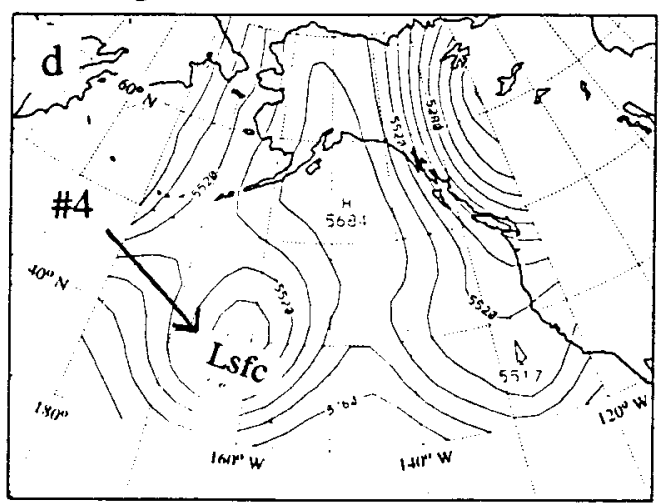

FIG. 3. As in Fig. 2 except for (a) 0000 UTC 18 November, (b) 0000 UTC 19 November, (c) 0000 UTC 22 November, and (d) 1800 UTC 24 November 1985.

$\mathrm{hPa}$ were examined. In addition, height tendencies were composited by time-averaging the height tendencies at the center point of the block over each period (see Fig. 1). This averaging acts like a low-pass filter and yields height tendencies for each term on the left- and righthand sides of (1) and (2) that are not contaminated by high-frequency transients embedded within the flow field. It is desirable to remove some of the higher-frequency components of the height tendency when examining long-lived phenomena, such as blocking, since minor oscillations (e.g., Fig. 1) in the height tendencies may not be representative of processes contributing to block development, maintenance, or decay (R. Dole 1995, personal communication). However, the length of the time intervals can be chosen so as to retain the influence of relevant synoptic-scale features that impact on block evolution. The center point was chosen for this procedure because at that point the propagation component is zero, and, therefore, the height tendencies there correspond to development. The total $\mathrm{Z}-\mathrm{O}$ tendency and each forcing term on the right-hand side of (2) that are averaged over each time period (e.g., development) are displayed using bar graphs. The discussion of block evolution will focus on these composite bar graphs. Finally, the map depictions shown in the following subsections were chosen by selecting the map time within each period whose center point bar graph best fit the corresponding composite bar graph.

\section{a. The Atlantic blocking event}

The development period of the Atlantic blocking event is represented by 0600 UTC 13 November 1985. As indicated in Fig. 4a, the ridge center was located under a region of 500-hPa height falls. Height rise maxima were located to the south and east of the block center and comprised a height rise region that was oriented southwest-northeast across the map region. Only after 0600 UTC 13 November was the ridge axis/block center located within the region of total calculated $\mathrm{Z}-\mathrm{O}$ height rises.

The first of two intensification periods that were observed with this case was influenced by two associated surface cyclones that developed after onset. Therefore, this initial intensification period was broken down into two subperiods in an attempt to isolate block intensification before (Figs. 4b and 5b) and after (Figs. 4c and $5 c$ ) the second of the two cyclones developed (number 

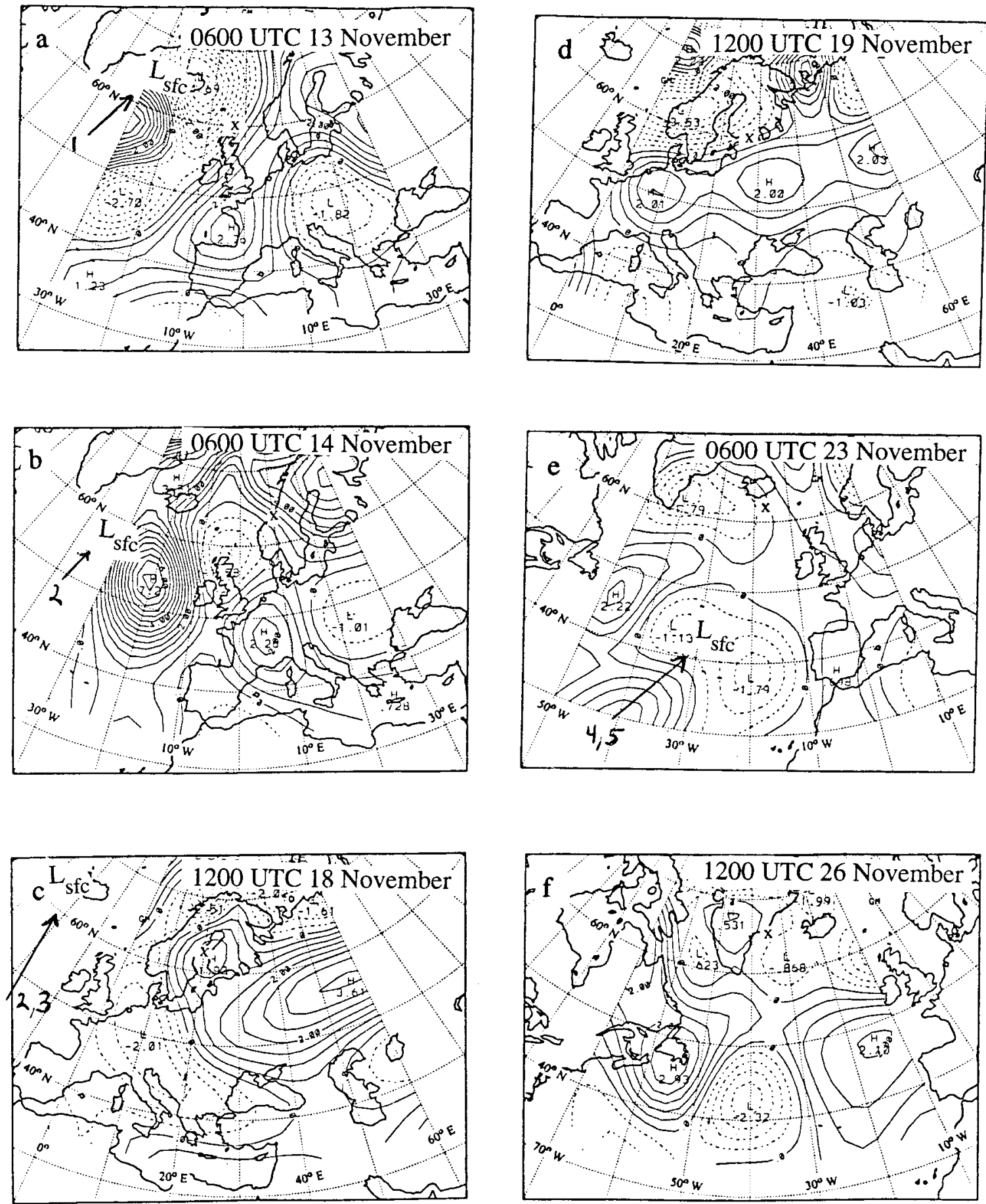

FIG. 4. Regional total Z-O 500-hPa calculated height tendency fields for (a) 0600 UTC 13 November, (b) 0600 UTC 14 November, (c) 1200 UTC 18 November, (d) 1200 UTC 19 November, (e) 0600 UTC 23 November, and (f) 0000 UTC 25 November 1985. The block center is marked with an " $\mathrm{X}$ " and the units are $0.5 \times 10^{-3} \mathrm{~m} \mathrm{~s}^{-1}$.

3 in Fig. 2). The first part of the initial intensification period is represented by 0600 UTC 14 November. The block center point was within a large region of height rises, with a maximum located northeast of the block center (Fig. 4b). The second part of the initial intensi- fication period is represented by 1200 UTC 18 November. The block center was located very close to a maximum region of height rises over Finland (Fig. 4c).

The block intensification was interrupted by a midlife decay period after 0000 UTC 19 November and is rep- 

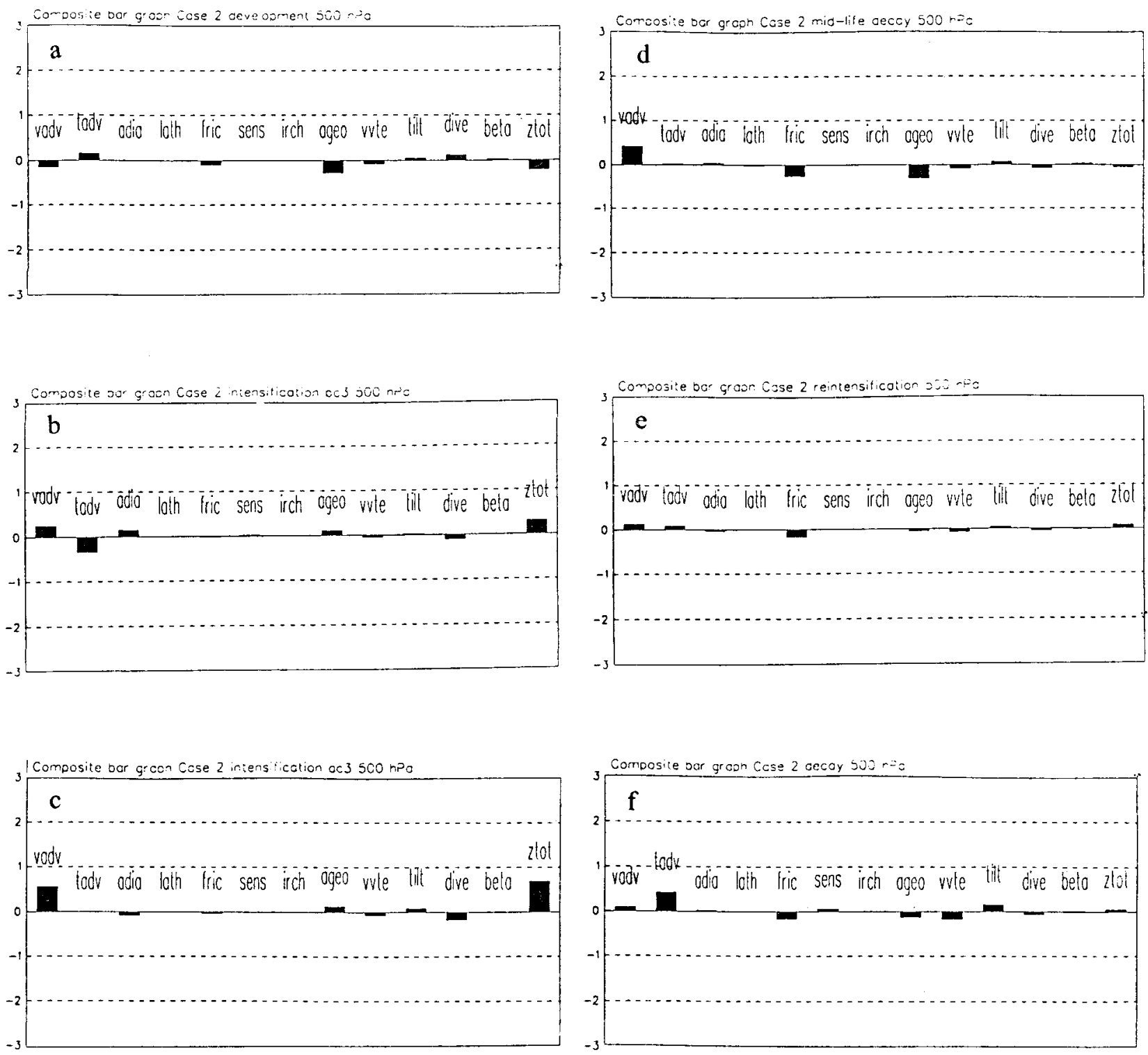

FIG. 5. Composite bar graphs for total calculated height tendencies and each term in Eq. (1) for the (a) development, (b) intensification associated with the first cyclone, (c) intensification associated with the second cyclone, (d) midlife decay, (e) second intensification period, and (f) final decay period for the Atlantic blocking event. Units are $10^{-3} \mathrm{~m} \mathrm{~s}^{-1}$.

resented by 1200 UTC 19 November (Fig. 4d). The block center was located just within a region of height falls located over much of northern and western Europe. A second intensification period of this blocking event began after 1800 UTC 20 November and is represented here by 0600 UTC 23 November (Fig. 4e). The block was centered near a region of height rises that maximized to the north of the block center. The final decay period of this blocking event commenced at 0000 UTC 25 November and is represented by 1200 UTC 26 November (Fig. 4f). The total height tendency field reveals that the block center was located within a region of height falls that was interrupted only by a small-scale region of height rises over southern Greenland.
An examination of the composite bar graphs for development (Fig. 5a) indicates that, in general, height falls occurred over the block center. As shown by the example in Fig. 4a, however, the center was located between regions of strong height rises and strong height falls. Several mechanisms contributed to height rises through the development period, with the most dominant of these being the height rises produced by the temperature advection (tadv) term, contributing to $44 \%$ of the "development sum." The development sum (D-sum) is defined as the sum of all physical processes forcing height rises, that is, positive contributors to ridge development in the composite bar graphs. The vortex stretching term (dive, $34 \%$ of the D-sum) and vorticity 
tilting (tilt) term were the next largest contributors to height rises. The two primary contributors to the D-sum in this case are different from those of the case in LS95b (vorticity advection and adiabatic temperature change).

The composite bar graphs for each part of the initial intensification indicate that each experienced strong height rises as calculated by the $\mathrm{Z}-\mathrm{O}$ equation. However, the contributing mechanisms to these total height rises before and after the development of the second cyclone are slightly different. During and after the development of the first cyclone (number 2, Fig. 5b), the height rises at the block center were dominated by anticyclonic vorticity advection (AVA; $51 \%$ of the D-sum), adiabatic temperature change (adia; 29.5\%), and ageostrophic vorticity tendencies (ageo; 22\%). By this time, temperature advection had become the primary inhibitor to development. During and after the development of the second cyclone (number 3, Fig. 5c), AVA was a more dominant mechanism (70\% of the D-sum), followed by ageostrophic vorticity tendencies (17\%), and vorticity tilting (11.5\%). The dominance of AVA throughout this intensification is similar to the intensification of LS95b.

During the intermediate decay period (Fig. 5d), AVA was again the dominant mechanism forcing height rises (72\% of the D-sum) in the block center. Other mechanisms that contributed significantly to height rises were vorticity tilting $(13 \%)$ and adiabatic temperature change (7\%). The vorticity tilting was offset by the vertical advection of vorticity. Therefore, the contributions due to boundary layer friction and ageostrophic processes were more than enough to overcome the constant contribution to block intensification by AVA. The second intensification period was characterized by minor oscillations in central height values, but the overall trend was for higher central height values (see Fig. 1a). As a result, although Fig. 4e (0600 UTC 23 November) shows the block center near the zero-tendency isopleth, the composite bar graph (Fig. 5e) reflects the general height rise trend. An examination of the bar graph shows that during the second intensification height rises were dominated by AVA (51\% of the D-sum), temperature advection (33\%), and vorticity tilting (16\%).

Note that the composite bar graph in Fig. 5f indicates net height rises for the final decay period even though the center point height values (Fig. 1a) indicate that the block became less intense. The temperature advection term was the dominant mechanism forcing height rises (Fig. 5f). This term contributed to $55 \%$ of the D-sum during decay. While the bar graph shows that the above result is not consistent with decay, or the decay of the blocking event of LS95b, the other mechanisms exhibit features that were consistent with that case. For example, the vorticity advection, the vorticity tilting term, and the adiabatic temperature change all contributed to height rises. All other terms contributed to the decay of the block, with the most dominant of these terms being boundary layer friction, ageostrophic vorticity tendencies, and vertical vorticity advection.

\section{b. The Pacific case}

The development period of this blocking event is represented by 0000 UTC 19 November (Fig. 6a), which is the time of block onset. An area of height rises (falls) was located to the east (west) of the block center. The intensification period for this case is represented by 0600 UTC 20 November 1985 (Fig. 6b). The block center was now clearly located within a broad region of height rises that covered Alaska and the surrounding area of the North Pacific. The primary height rise maximum was east of the block center, while a secondary maximum was located to the west. During the maintenance period, there was little change in the overall $500-\mathrm{hPa}$ center point height (Fig. 1b) for the Pacific blocking event (represented by 0600 UTC 22 November). The total height tendency map (Fig. 6c) shows that the block center was located within a region of 500-hPa height rises, which maximized just east of the block center. The decay of this blocking event began following 1200 UTC 23 November and is represented by 1200 UTC 25 November (Fig. 6d). The block center was located within a region of height falls extending north from a broad area of height falls located over the east-central Pacific.

The composite bar graph for the $\mathrm{Z}-\mathrm{O}$ total tendencies indicates that, during development (Fig. 7a), and like the Atlantic blocking event (unlike LS95b), height falls occurred in the ridge center. The vorticity advection term exhibits almost no tendency during this period, which is the result of strong height falls (rises) that occurred during the first (second) $24 \mathrm{~h}$ of this period. Temperature advection contributed weak height rises to the composite total height tendencies. This term evolved in a similar manner to the vorticity advection term throughout development. The contributors to height rises during development were vorticity tilting, the vortex stretching, and temperature advection, which contributed to $47 \%, 31 \%$, and $22 \%$ of the D-sum, respectively.

The intensification composite bar graph (Fig. 7b) demonstrates that AVA was the predominant mechanism contributing to height rises (40\% of the D-sum). Adiabatic temperature change also contributed significantly to height rises $(28 \%)$, followed by vorticity tilting (17\%) and ageostrophic tendency (13\%). During intensification, the temperature advection and the vortex stretching terms became significant inhibitors of development, a role opposite to that played by both during development. The vorticity advection term continued as the largest contributor to height rises during the maintenance period (56\% of the D-sum; Fig. 7c). Ageostrophic vorticity tendencies and vorticity tilting also contributed to height rises (21\% and $15 \%$ or the D-sum, respectively), while temperature advection and boundary layer friction were the greatest contributors to height falls. Again, the predominance of AVA during these periods is similar to that of LS95b.

The composite bar graph for the decay period (Fig. 7d) of this event indicates that only the vorticity tilting and divergence terms contributed significantly to height 

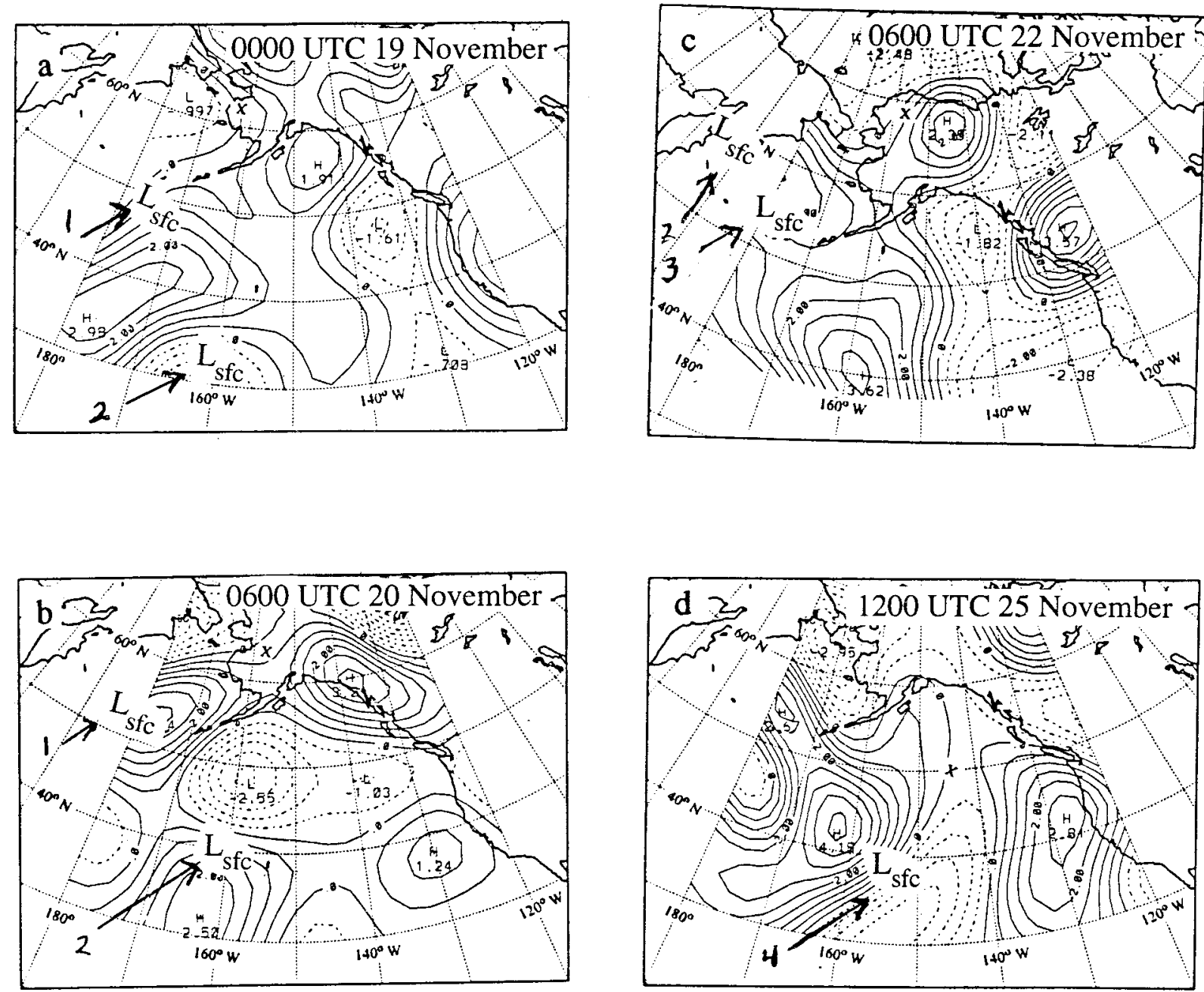

FIG. 6. As in Fig. 4 except for (a) 0000 UTC 19 November, (b) 0600 UTC 20 November, (c) 0600 UTC 22 November, and (d) 1200 UTC 25 November 1985 .

rises ( $50 \%$ and $25 \%$ of the D-sum, respectively). Several terms made smaller contributions to the composite height rises. Unlike the Atlantic and the LS95b blocking event, vorticity advection contributed height falls to the $500-\mathrm{hPa}$ total $\mathrm{Z}-\mathrm{O}$ height tendencies, perhaps in association with the advancing upstream 500-hPa trough noted in section $4 \mathrm{~b}$. Mechanisms contributing to height falls, or to decay, were ageostrophic tendencies, vorticity advection, boundary layer friction, and the vertical advection of vorticity.

\section{Scale-partitioning results}

An overview of the scale-partitioned results will, again for brevity and consistency, apply the same representative map times used throughout section 5. In addition, a detailed discussion of the results is restricted to total partitioned 500-hPa height tendency fields and anticyclone center statistics to focus on the influence of the partitioned forcing terms on block development. No compositing was done, as in section 5, since important features in the synoptic-scale and interaction components of height tendency field may be eliminated or "smoothed out" in the process.

\section{a. The Atlantic blocking event}

The distribution of the $P$ height tendency field (Fig. 8a) was similar to the total tendency (Fig. 4a) especially in the region of the block center. The $S$ height tendency field (Fig. 8b) was similar to the $P$ height tendency in that height rises (falls) dominated the eastern (western) half of the field. However, the regions of maximum height tendency were located farther south and west than those in the $P$ height tendencies, and after 0600 UTC 13 November, $S$ height rises were located over the block center (not shown). The distribution of interaction height tendencies (Fig. 8c) was much less coherent than 

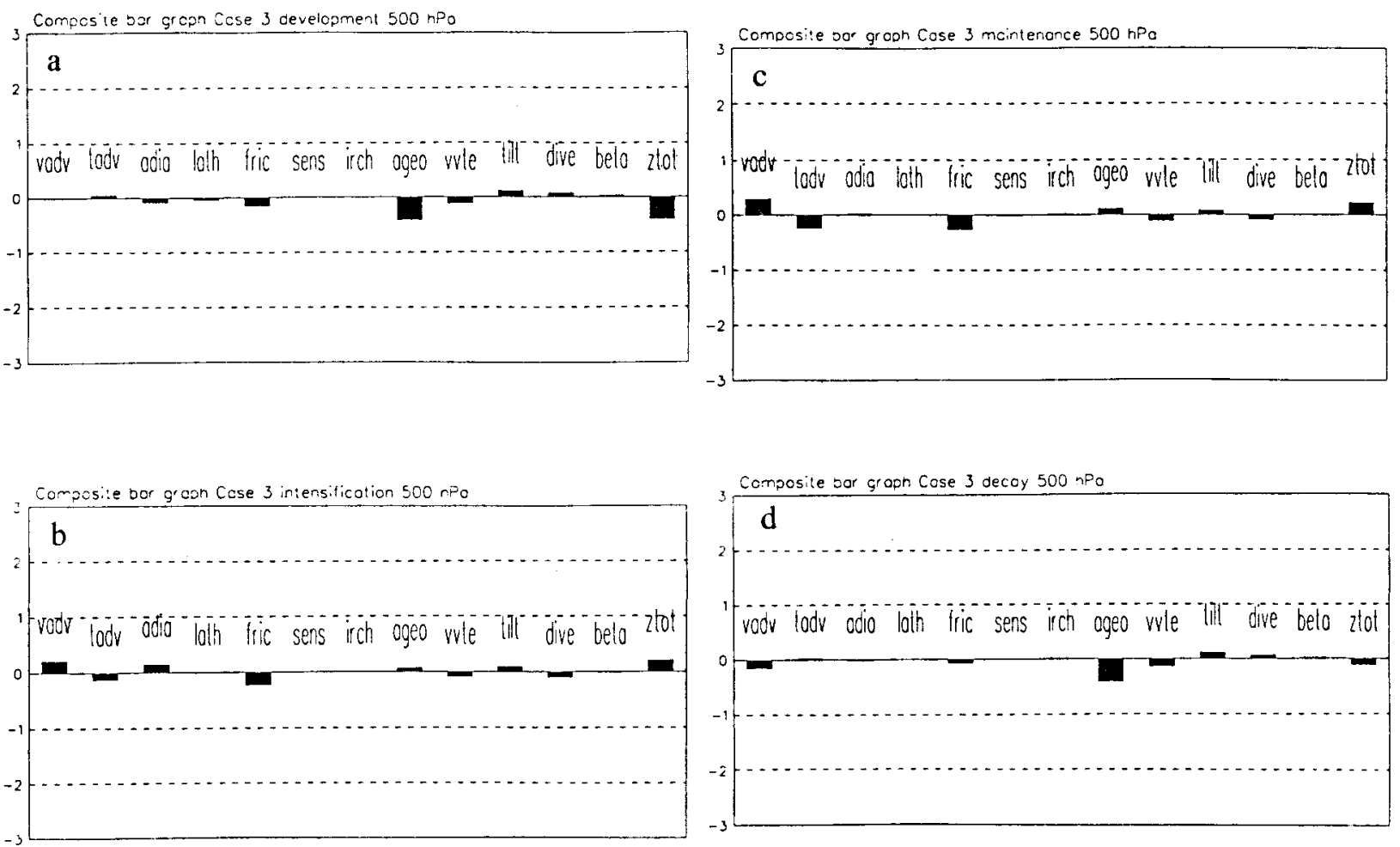

FIG. 7. As in Fig. 5 except for the Pacific region blocking event where (a), (b), (c), and (d) are the development, intensification, maintenance, and decay, respectively.

the $P$ and $S$ components, and the block center was located near a zero-tendency line. An examination of center point contributions (Table 1 ) reveals that the $P$ component was the largest contributor to height falls at the block center. Both the $S$ and $I$ components were forcing height rises over the ridge center.

During the first part of intensification (associated with the first interacting cyclone during this period; see sections $4 \mathrm{a}$ and $5 \mathrm{a}$ ), the block center was located primarily within a region of height rises (Fig. 4b). Planetary-scale height rises covered most of the field and maximized both east and west of the block center at this time (Fig. 9a). The $S$ component (Fig. 9b) exhibited height rise maxima over central Europe and the eastern Atlantic. However, the $S$ component contributed weak height falls to the region over the British Isles that encompassed the block center. The block center was squarely in the $I$ term height rise region located over Scandinavia and most of Europe. Table 1 shows that the height rises over the block center were largely due to the $P$ component, with a secondary contribution from the $I$ terms.

In the second part of the intensification period, after the second cyclone developed, strong height rises predominated within the block center. A region of $P$ height rises was located east of the block center (Fig. 10a) and comprised the east-central portion of the total height rise region. Synoptic-scale height rises were located over northern Scandinavia and eastern Europe (Fig. 10b). These comprised the western portion of the total height rise region, including much of the maximum over Finland. The contribution by the interaction component (Fig. 10c) shows that the $P, S$, and $I$ components contributed to (at least part of) the large height rise region over Russia. There were weak height rises due to the $I$ component over the block center. Table 1 shows that the strong height rises over the center of the block at this time were forced primarily by the $S$ component, perhaps because of the second cyclone influence, but with a supporting role played by the $I$ component. The $P$ component opposed intensification during this period.

The midlife decay period was characterized by height falls over Scandinavia and western Europe, with strong height rises still located to the south and east of the block center (Fig. 4d). The northern region of the total height fall area was largely composed of $P$ height falls (Fig. 11a). The $S$ height tendency field (Fig. 11b) shows that height rises were the rule over much of Europe and eastern Scandinavia. Therefore, the $P$ and $S$ height tendencies were of opposite sign within the block center. The $I$ height tendency field (Fig. 11c) indicates that height rises were occurring over eastern Europe and western Russia and these maxima were coincident with maxima in the $S$ height tendency field. An examination of Table 1 shows that over the block center, the $P$ height falls exceeded the combined height rises forced by the $S$ and $I$ com- 

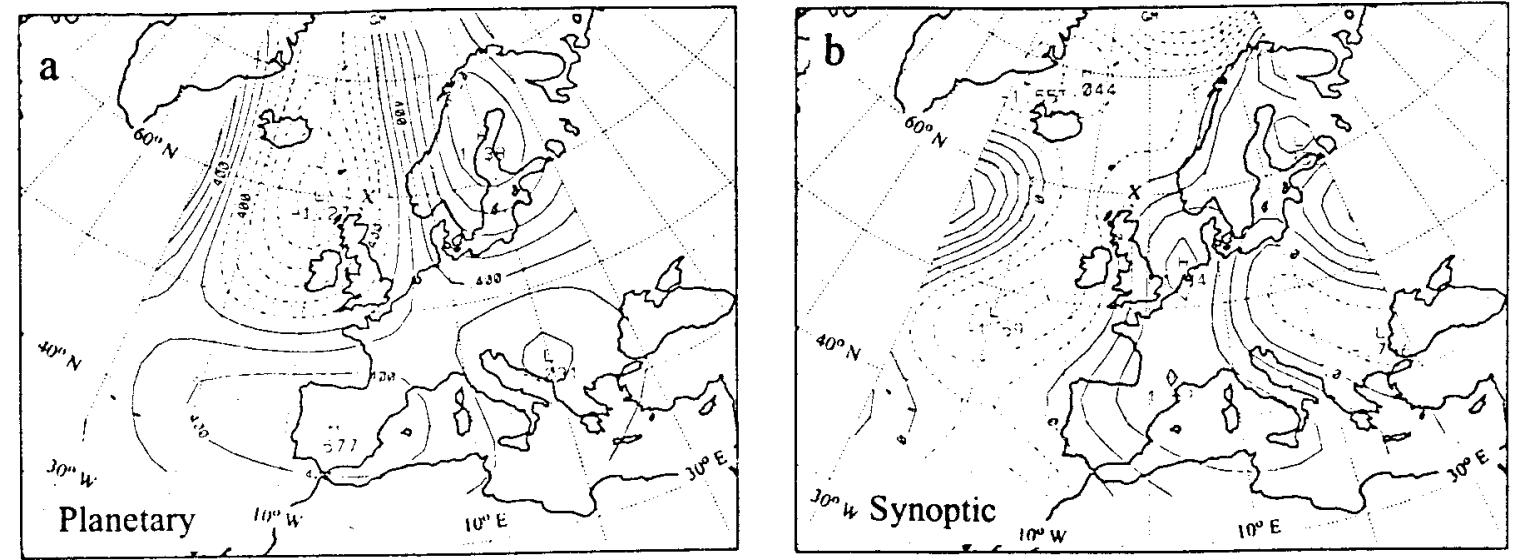

0600 UTC 13 November

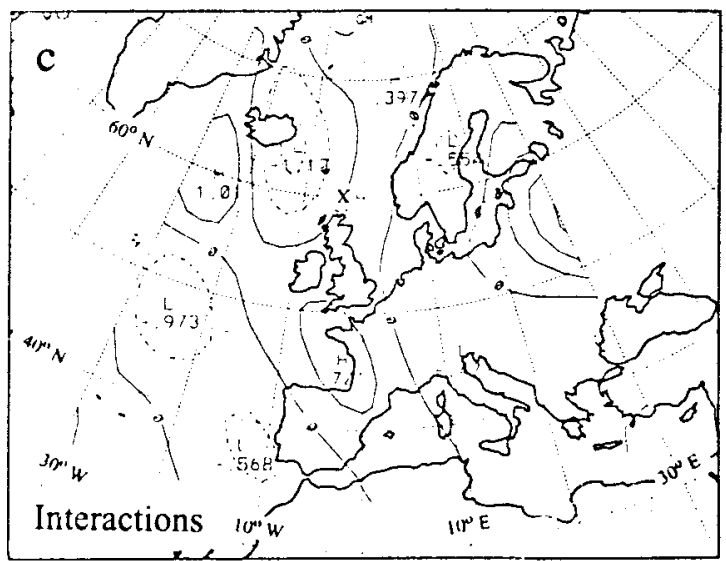

FIG. 8. Total height tendencies as calculated by the partitioned Z-O equation for the (a) planetary-scale, (b) synoptic-scale, and (c) planetary/ synoptic-scale interactions of each component on 0600 UTC 13 November 1985. The block center is marked with an "X" and the units are (a) $0.2 \times 10^{-3}$, (b) and (c) $0.5 \times 10^{-3} \mathrm{~m} \mathrm{~s}^{-1}$.

TABLE 1. Center-point height tendencies for the planetary-scale $(P)$, synoptic-scale $(S)$, and interaction $(I)$ components $\left(\times 10^{-3} \mathrm{~m} \mathrm{~s}^{-1}\right)$.

\begin{tabular}{|c|c|c|c|c|}
\hline Date & Planetary-scale & Synoptic-scale & Interaction & $P+S+I$ \\
\hline \multicolumn{5}{|l|}{ Atlantic case } \\
\hline 0600 UTC 13 November & -0.705 & 0.115 & 0.038 & -0.552 \\
\hline 0600 UTC 14 November & 0.436 & -0.103 & 0.218 & 0.551 \\
\hline 1200 UTC 18 November & -0.795 & 1.564 & 0.256 & 1.025 \\
\hline 1200 UTC 19 November & -0.795 & 0.662 & 0.115 & -0.018 \\
\hline 0600 UTC 23 November & -0.013 & 0.030 & -0.038 & -0.021 \\
\hline 1200 UTC 26 November & -0.244 & -0.282 & 0.006 & -0.52 \\
\hline \multicolumn{5}{|l|}{ Pacific case } \\
\hline 0000 UTC 19 November & 0.500 & -0.526 & 0.021 & -0.005 \\
\hline 0600 UTC 20 November & -0.256 & 0.359 & 0.141 & 0.244 \\
\hline 0600 UTC 22 November & -0.372 & 0.346 & 0.154 & 0.128 \\
\hline 1200 UTC 25 November & 0.397 & -1.013 & -0.385 & -1.001 \\
\hline
\end{tabular}



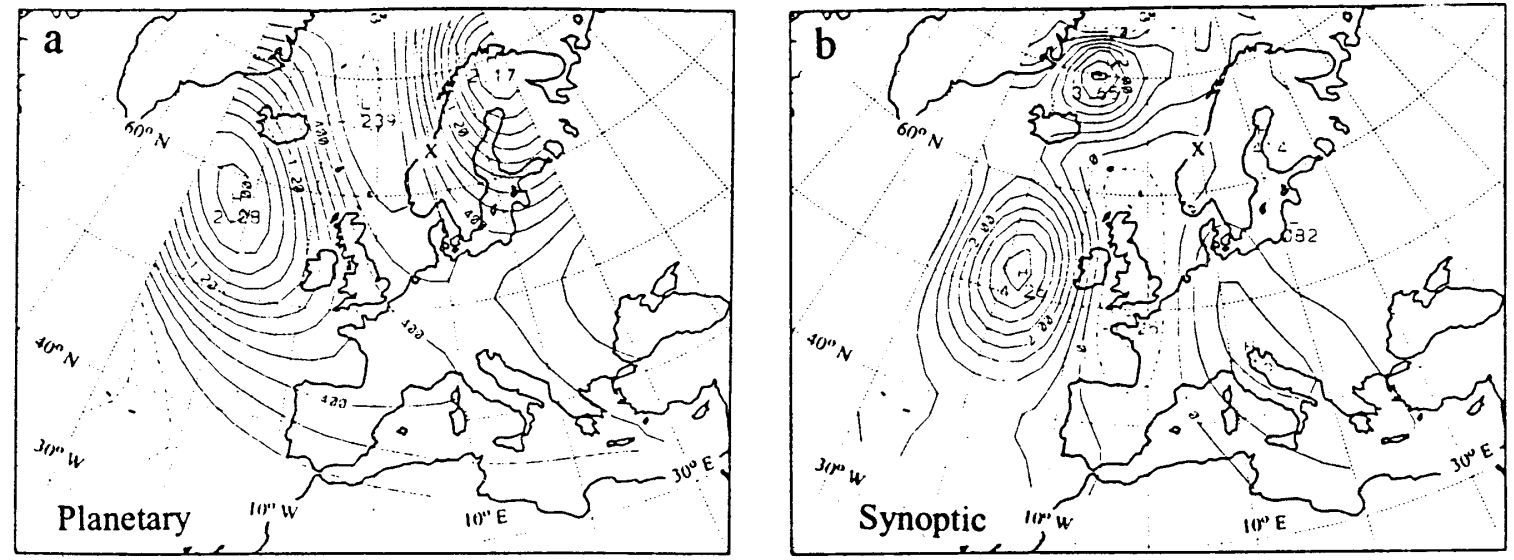

\section{UTC 14 November}

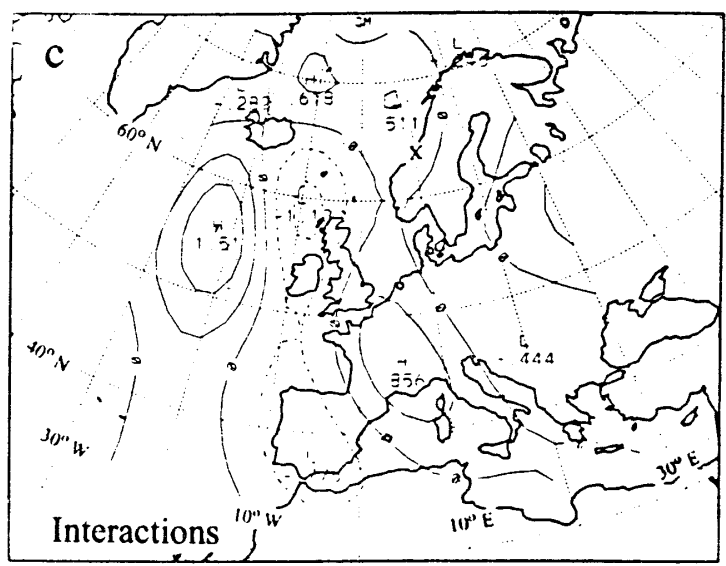

FIG. 9. As in Fig. 8 except for 0600 UTC 14 November 1985.

ponents. Recall from Fig. 10, for the $24 \mathrm{~h}$ previous, that $S$ and $I$ height rises exceeded $P$ height falls.

The reintensification of the Atlantic case was characterized by rising heights (see Fig. 1a). The $P$ height tendency field (Fig. 12a) shows that the block center was located within the region of height falls that occurred over the North Atlantic. In the $S$ height tendency field (Fig. 12b), which was less coherent spatially than the $P$ height tendencies, height rises were indicated at the block center. The $I$ tendencies were weak across the display domain (Fig. 12c) and the block center was located within a region of $I$ height falls. Table 1 confirms that the block center was located within a region of weak total height falls, contributed by the $P$ and $I$ components. The $S$ component contributed weak height rises to the total field.

The map time used to represent decay shows that the block center was located within a region of height falls (Fig. 4f). In the $P$ height tendency field (Fig. 13a), height falls were occurring over Greenland, Iceland, and the surrounding region of the North Atlantic, including the area where the block was residing. Height rises forced by the $S$ component (Fig. 13b) were present over most of the region, except for a small area encompassing the blocking ridge and over Great Britain. The $I$ height tendency field (Fig. 13c) exhibited some (weaker) structure in the southern (northern) part of the map domain, and the block center, was also located near a zero tendency line. Table 1 shows that both the $P$ and $S$ components were contributing to the height falls that occurred over the block center, but the $I$ contribution was negligible.

\section{b. The Pacific blocking event}

At the map time used to represent development (Fig. $6 a)$, height rises were prevalent over most of the domain, including the eastern portion of the ridge axis, while 

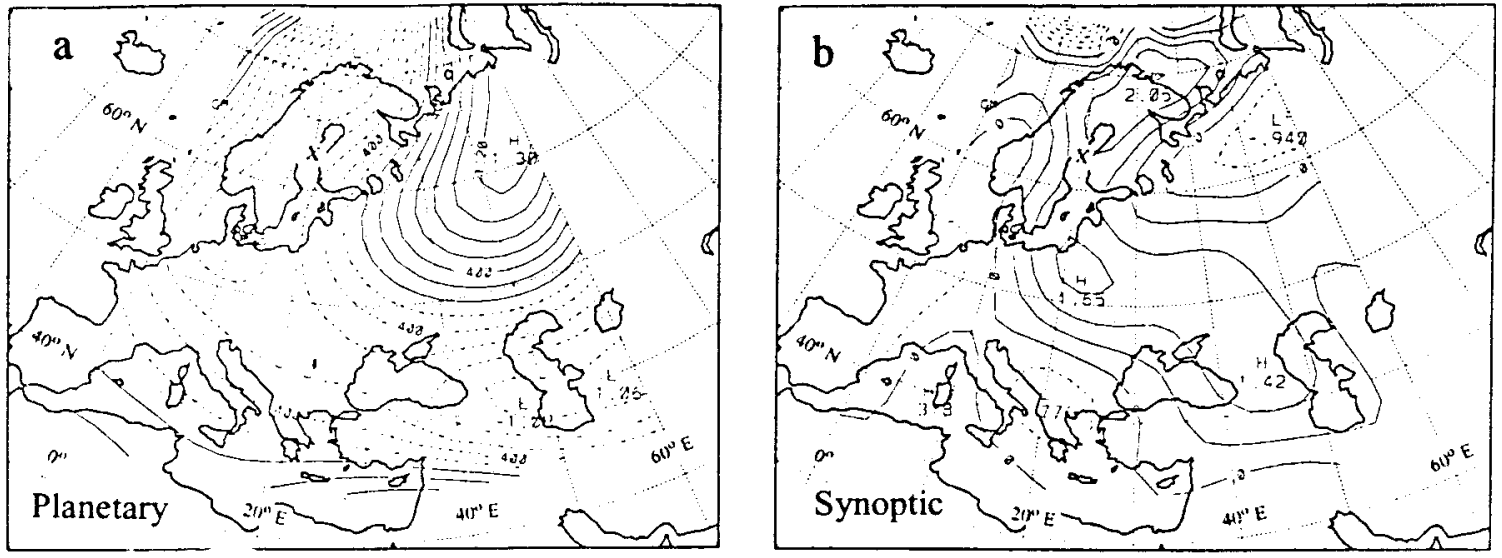

1200 UTC 18 November

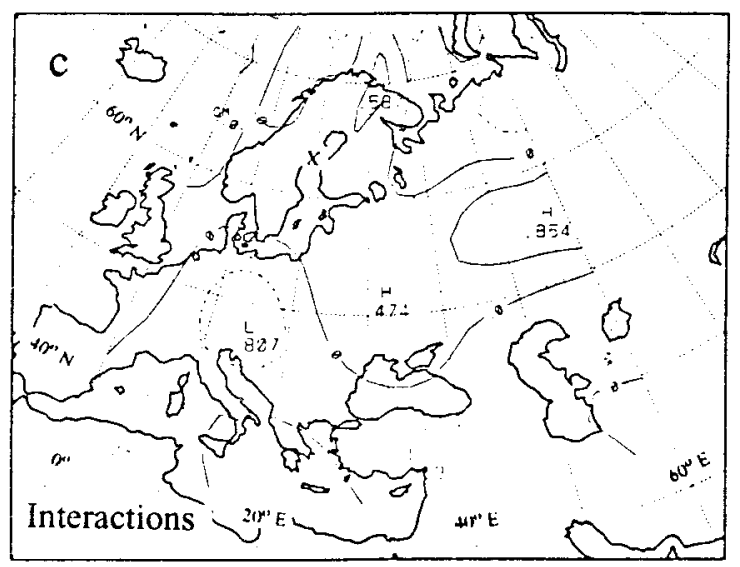

FIG. 10. As in Fig. 8 except for 1200 UTC 18 November 1985.

height falls could be found to the southeast near the west coast of North America. Planetary-scale height rises (Fig. 14a) were occurring over most of the map domain, including the developing ridge. Height falls due to the $S$ component (Fig. 14b) occurred over Alaska, including the northern portion of the developing ridge, and over most of the eastern portion of the domain. An examination of the $I$ field (Fig. 14c) reveals that height rises were prevalent over a majority of the display region, including in the ridge axis (Alaska). Table 1 indicates that the weak height falls found over the center of the ridge axis at this time resulted from the near cancellation of the $P$ and $S$ height tendencies, while $I$ contributed weak height rises to the total tendency.

The intensification of this blocking event was associated with strong height rise regions occurring over the northern and southern portion of the domain, which included the block center, but height falls over the Gulf of Alaska (Fig. 6b). Planetary-scale processes (Fig. 15a) forced height falls in the center and on the western flank of the ridge. The $S$ tendency field (Fig. 15b) shows that height rises were forced over the block center and over southern Alaska; this field looked the most similar to the total field at this time. Two $I$ height rise maxima (Fig. 15c) were occurring both east (northwest Canada and Alaska) and west of the block center, and included the center. In Table 1 it can be seen that total height rises were forced as the total $S$ and $I$ components overcame height falls forced by the $P$ component.

At the map time chosen to represent the maintenance period, height rises were occurring over much of the western portion of the display region, including the block center, while height falls were occurring over the eastern half (Fig. 6c). The distribution of $P$ height tendencies (Fig. 16a) was similar to the total height tendencies below $50^{\circ} \mathrm{N}$ and $P$ component height falls oc- 

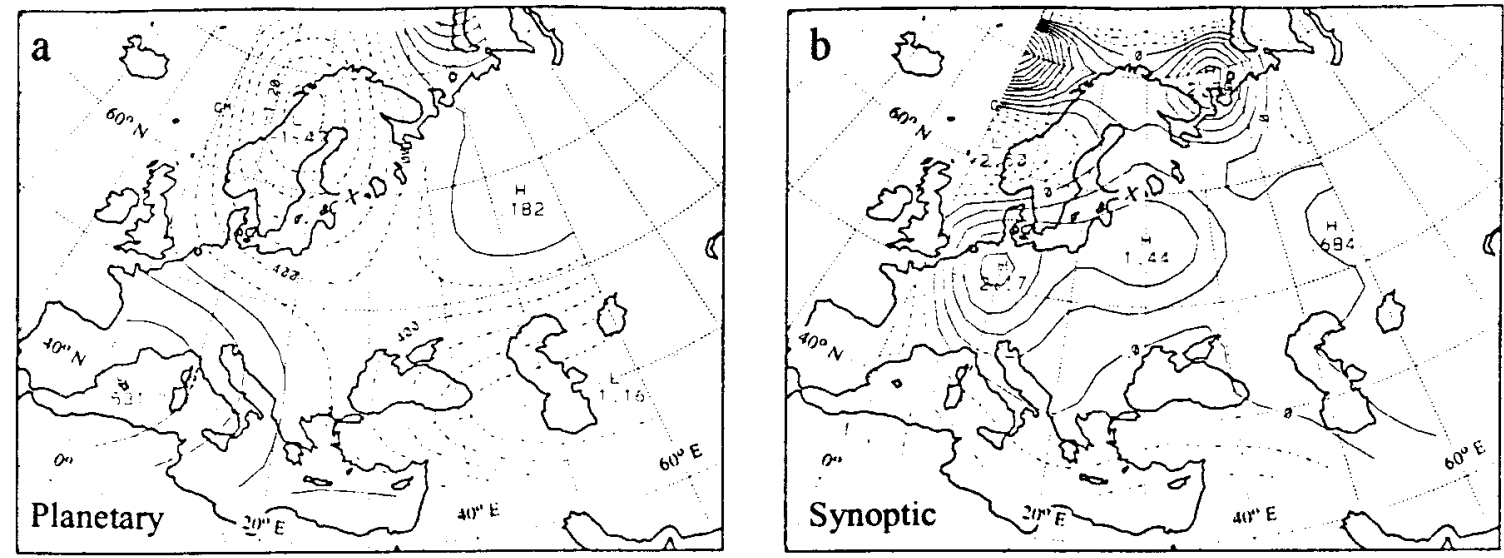

1200 UTC 19 November

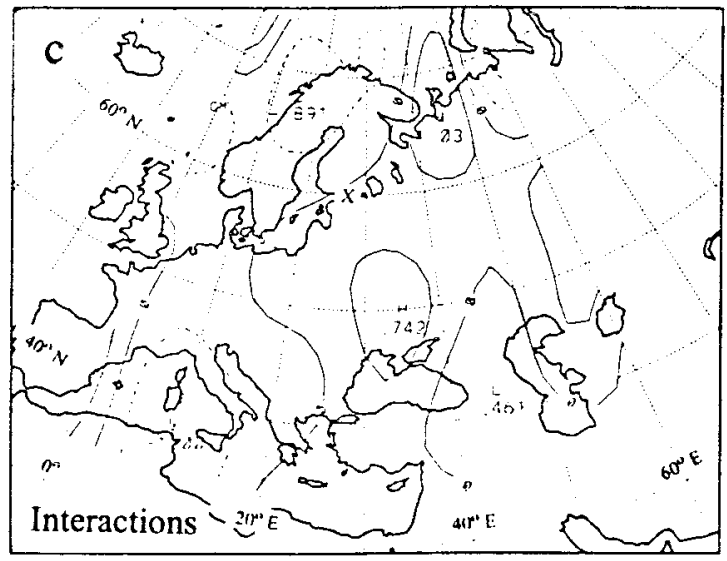

FIG. 11. As in Fig. 8 except for 1200 UTC 19 November 1985.

curred over Alaska, including the block center. Synoptic-scale height rises (Fig. 16b) were occurring over most of the domain, with a height rise maximum over the east-central Pacific. The I component (Fig. 16c) shows height rises over much of the northern part of the map region, including Alaska and the block center, and over southwestern Canada. The total height rises at the block center (Table 1) could be described as the net balance between the $S$ and $I$ components, which were both forcing height rises, and the $P$ component, which was forcing height falls.

Decay was characterized by the occurrence of height falls over much of the ridge (Fig. 6d). The $P$ height tendency field (Fig. 17a) shows height rises (falls) in the northern and western (southeastern) portion of the domain. The distribution of the $S$ height tendencies (Fig. $17 \mathrm{~b})$ were nearly opposite the $P$ component. Height falls due to the $I$ components (Fig. 17c) occurred over most of the ridge area, and, because of the near cancellation by $P$ and $S$, the $I$ height tendencies resembled the total field (see Fig. 6d). Height falls over the block center (Table 1), however, were the result of a near cancellation between $P$ and $I$, as $S$ and $I$ overcame height rises due to the $P$ component.

\section{Discussion: The connection between the Atlantic and Pacific case}

Recall that periods of the Pacific and Atlantic cases overlapped for about 9 days and thus constituted a case of "double" or "simultaneous" blocking. One of the issues to be addressed regarding double blocking is whether there is a dynamic connection between the two; that is, does blocking in one part of the Northern Hemisphere preferentially accompany, trigger, or suppress blocking in another part of the hemisphere, or is there no connection at all between their concurrent existence? Austin (1980) and Colucci et al. (1981) showed that the 

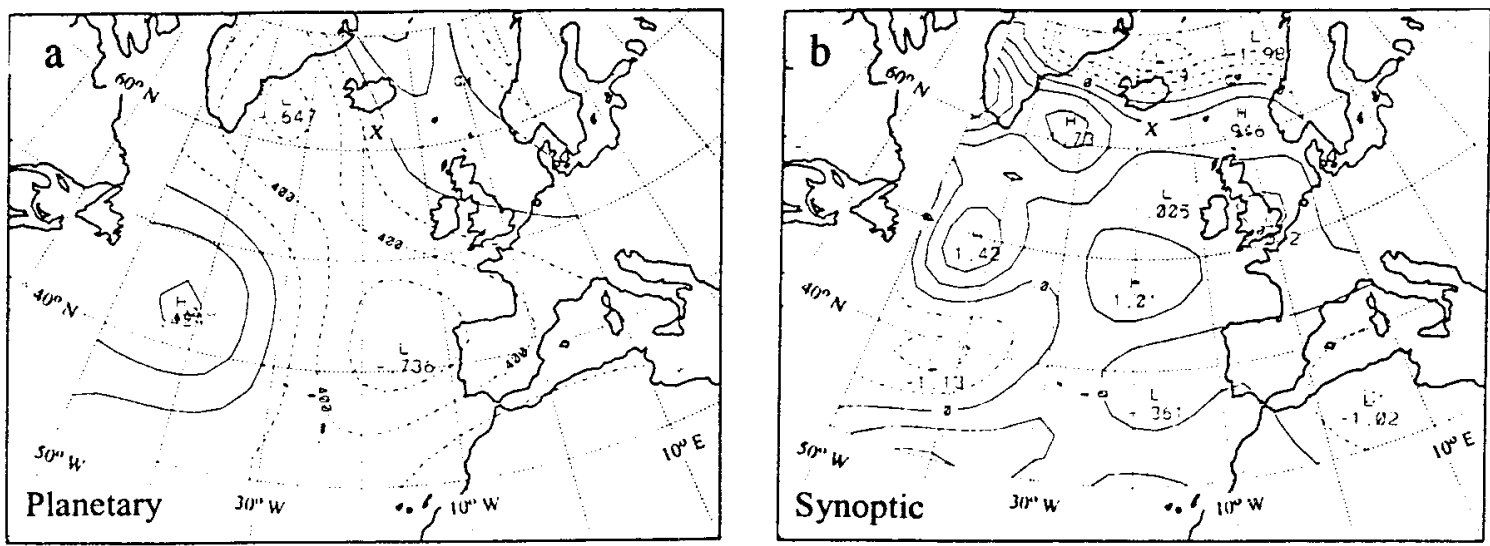

0600 UTC 23 November

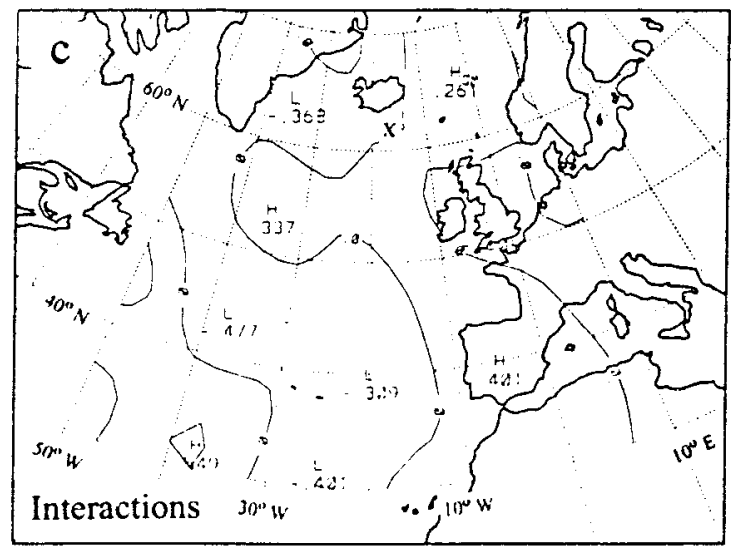

FIG. 12. As in Fig. 8 except for 0600 UTC 23 November 1985.

amplification and/or the constructive interference (or resonance) of hemispheric wavenumbers 1, 2, and 3 are involved in blocking events. Austin (1980) also showed that these wavenumbers are all highly amplified during simultaneous blocking events. These results do not in themselves provide an answer regarding the dynamic connection question but do suggest that double blocking would be associated almost exclusively with a high amplitude planetary-scale flow regime (mode 2; see Hansen 1986 or Sutera 1986) as was the case in this study. Trenberth and Mo (1985) studied a case of "triple blocking" in the Southern Hemisphere focusing on amplifying and prominent wavenumber 3 . They concluded that it was not clear if the enhancement of hemispheric wavenumber 3 was responsible for the occurrence of the triple block. They also concluded definitively that transients play a key role in the maintenance of blocks. Therefore, with regard to the question of simultaneous blocking being related, they stated that based on their work "both possibilities appear to prevail at certain times.” Quiroz (1987) and Lejenas and Madden (1992) found that a significant number of blocking events occur in association with a traveling hemispheric wavenumber 1 , which would imply that blocking could be favored or enhanced in the ridge and discouraged or damped in the trough. Further, it could be argued that, in this case, a connection may exist based on the results of Quiroz (1987) and Lejenas and Madden (1992) since the midlife decay of the Atlantic block coincides with the intensification of the Pacific blocking event.

However, climatolgical studies show that the occurrence of simultaneous blocking events are rare. LS95a showed that simultaneous blocking occurred on only $7.3 \%$ of the total days during the entire study, a result that is consistent with those of Lejenas and Okland (1983). In their study, Lejenas and Okland (1983) showed statistically that there was no connection between the simultaneous occurrence of blocking events. Also, the model results of Shutts (1983) suggest that there may be no dynamic connection between the simultaneous occurrence of blocking anticyclones. In his experiments, he noted that only one block appears in a 

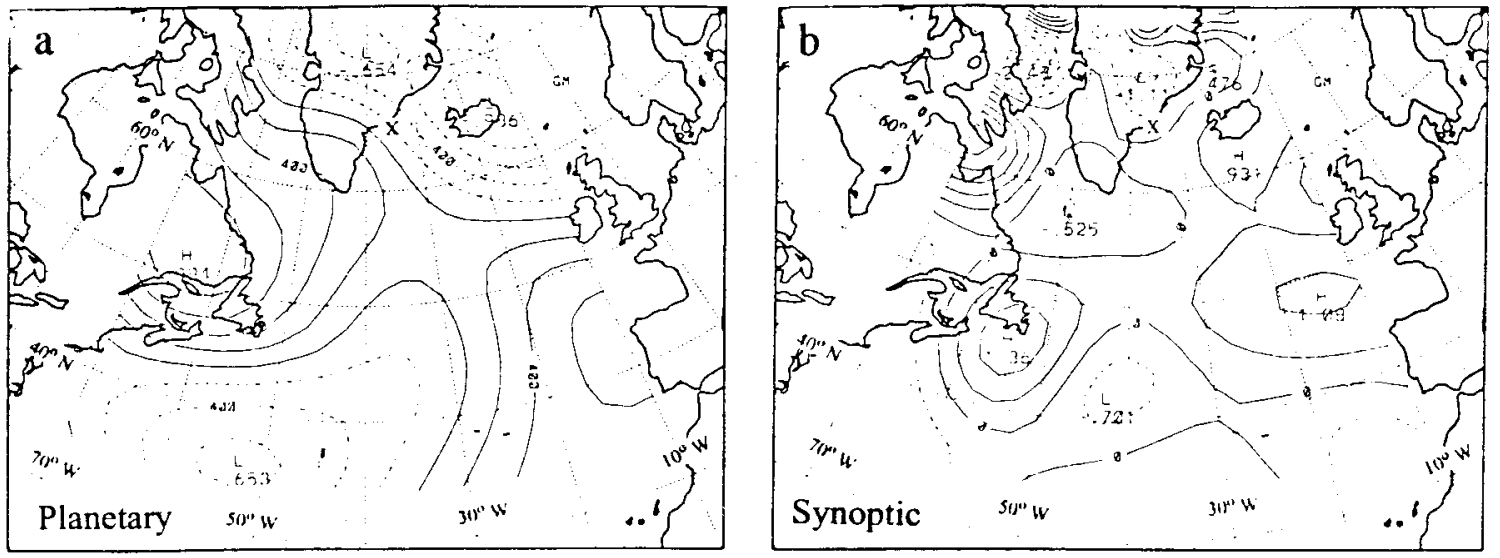

\section{UTC 26 November}

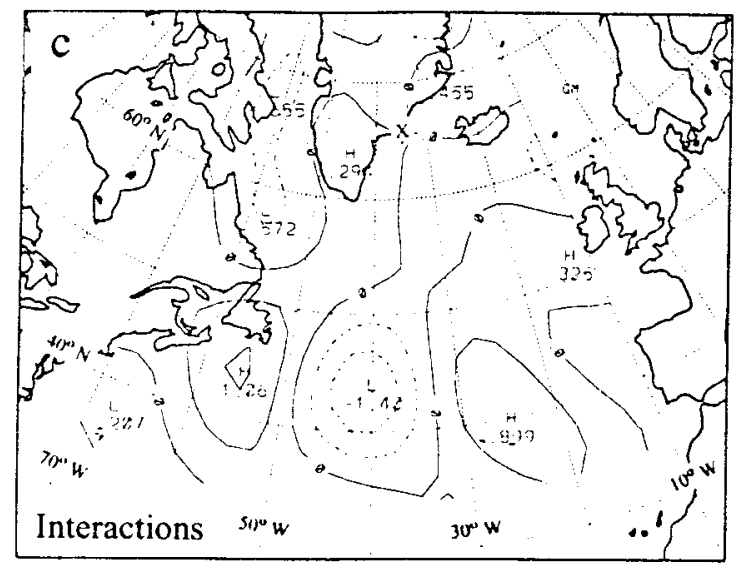

FIG. 13. As in Fig. 8 except for 1200 UTC 26 November 1985

channel, downstream from a smaller-scale "wavemaker," despite the fact that the streamfunction can be described by a stationary zonal wavenumber 3 . This implies that a proper phase relationship between the planetary and synoptic-scale forcing may be necessary for blocking, and, therefore, occurrence of simultaneous blocking may be more dependent on this phasing occurring independently in two different locations. Sections 4 and 5 show the association between block formation/intensification and upstream cyclones and their development as found by Tsou and Smith (1990) and LS95b for both blocking events. Also, the model studies of Kalnay-Rivas and Merkine (1981) show that the proper phasing of forcing on different scales (in their study, orography and thermal forcing, such as "sea surface temperature anomalies and even regions of enhanced baroclinicity, where repeated cyclogenesis may occur") may be necessary for block development. This idea is not new, however, since Rex (1950) noted that the Atlantic blocking action center was about $40^{\circ}-60^{\circ}$ longitude east of the Icelandic low. LS95a also showed that the upstream precursor cyclones to block formation occurred $10^{\circ}-50^{\circ}$ upstream of the block.

Given the strong relationship to planetary-scale flow described in the first paragraph, if the formation of the two blocks, whether simultaneous or lagged, were to act synergistically, one would expect that the $P$ component would force height rises over both ridges/blocks as they develop and intensify (or as the preexisting block is maintained and the lagged block develops) and that the $P$ component would be sufficient to overcome any opposition from the $S, I$, or both components. By using center point height tendencies in this diagnosis, the influence of planetary-scale wave amplification can be assessed since the $P$ height tendencies correspond to development. In each of the cases studied here, the $P$ height tendencies were of opposite sign during the development of the Pacific case (cf. Figs. 10 and 14 and 

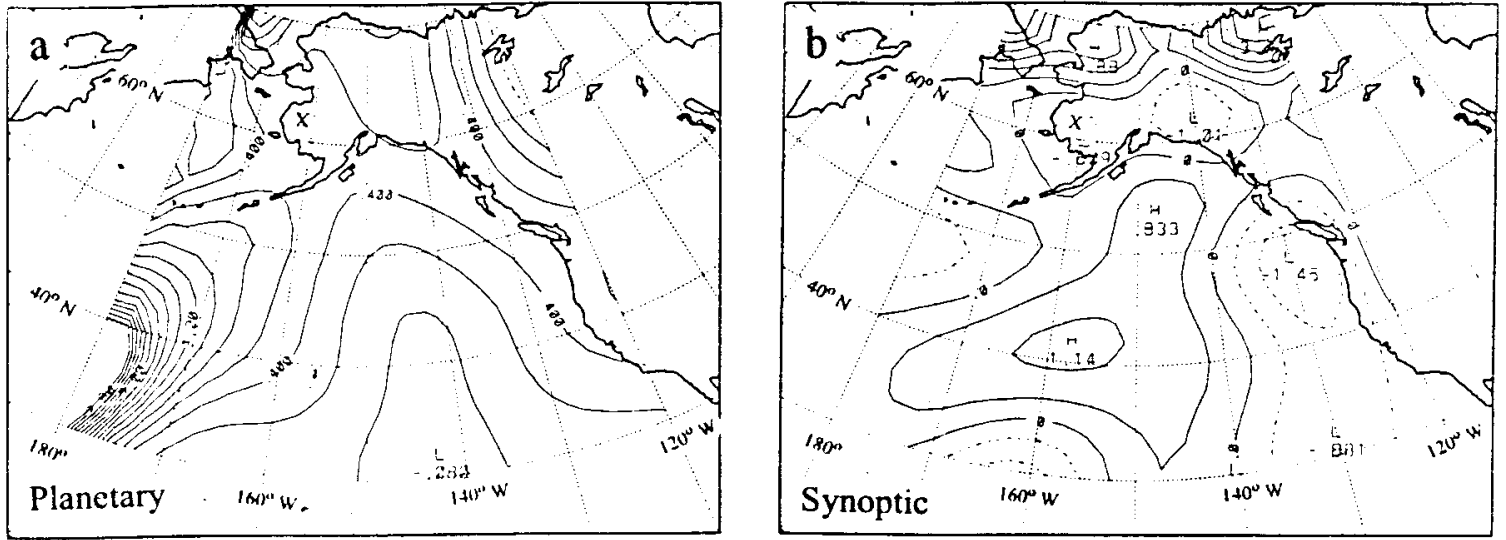

\section{UTC 19 November}

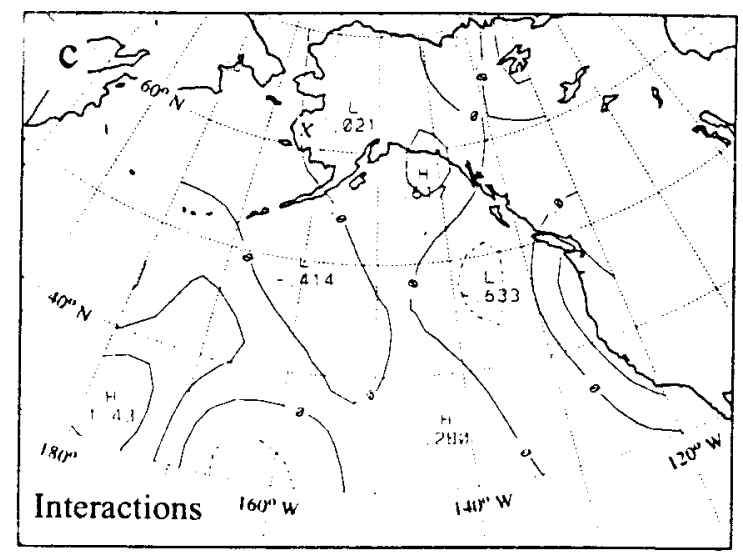

FIg. 14. As in Fig. 8 except for 0000 UTC 19 November 1985.

Table 1). On the other hand, if one block were to suppress formation of the other or if the formation of one were to lead to the decay of another, one would expect the $P$ component to force height rises over the forming block and height falls over the decaying block, and these again would be sufficient to overcome height tendencies forced by the $S$ and $I$ components. However, during the intensification of the Pacific block (midlife decay of the Atlantic block) $P$ height falls were occurring in the center of both blocks (cf. Figs. 11 and 15 and Table 1). The height falls occurring over both block centers during this period would not be consistent with the planetary-scale forcing being dominated by traveling or amplifying wavenumber 1 . Further, although $P$ did overcome the $S$ height rises in the Atlantic block (Fig. 11), this was not the case for the Pacific block (Fig. 15). Thus, these diagnostic results provide no evidence that there is a dynamic connection (via the planetary-scale component) between the occurrence of the simultaneous blocking events examined here. Instead, these results show that strong synoptic-scale or local forcing, acting with or opposed to planetary-scale forcing, can influence whether the block is intensifying or decaying, which would be consistent with previous model studies and LS95b. Finally, while it is true that the $I$ component contains a planetary-scale influence [see Eq. (6)], the $I$ component, during the time periods examined above, typically was of the same sign as $S$ (and opposite $P$ ) and much smaller than $P$ and $S$ (Table 1). Also, an examination of the horizontal maps shows that $I$ height tendencies have a spatial scale similar to $S$ height tendencies. This makes it difficult to establish that a dynamic connection between the blocking events occurred via the $I$ component.

The secondary objective was to compare these results to those of LS95b. It was shown in section 4 that the upstream cyclones, and their development, could be associated with block development and periods of block intensification (see Figs. 1-3). In both of these cases and that of LS95b, AVA was the most prominent contributor to height rises during block intensification and maintenance. During decay, boundary layer friction and ageos- 

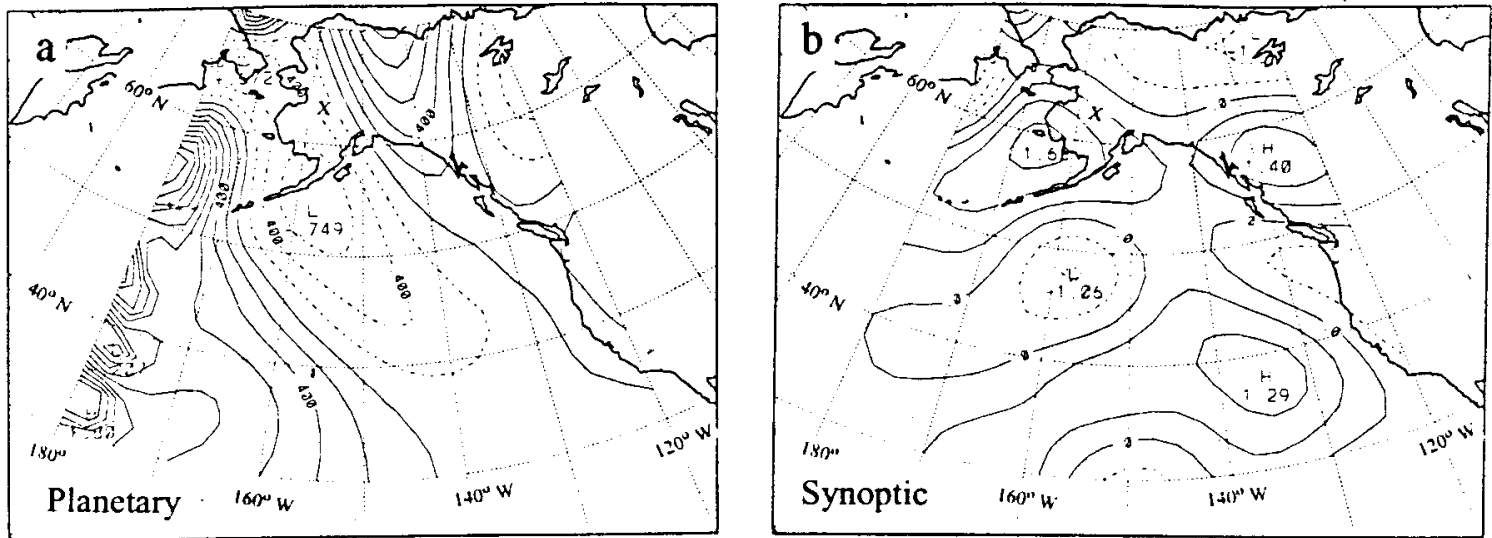

\section{UTC 20 November}

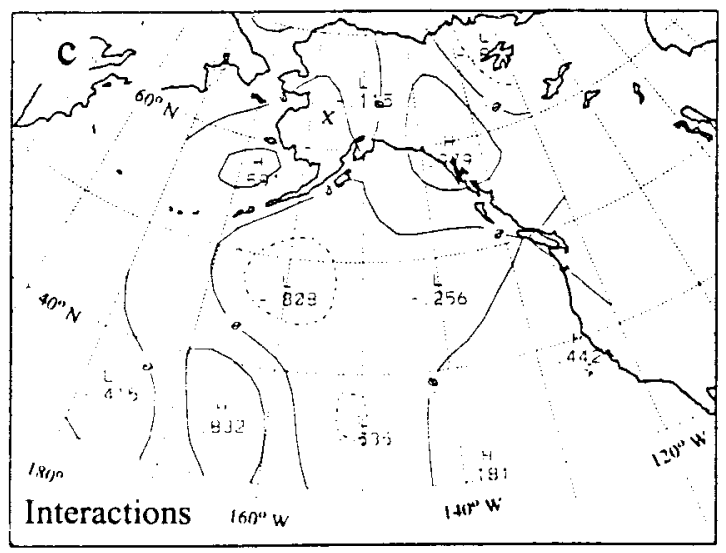

FIG. 15. As in Fig. 8 except for 0600 UTC 20 November 1985.

trophic processes were the most important contributors to height falls in all three cases. However, during formation, temperature advection was the most important contributor to height rises in these cases, while during the LS95b case, AVA was most prominent. This does not preclude the role of AVA as an important formation mechanism (as found by LS95b and many others) even though the composite results show that it was a small contributor to the formation of these two blocks. In both cases, the role of vorticity advection as a contributor occurred late in the development periods, offsetting its role as an inhibitor early when averaged over the whole period.

Using the wave amplitude index data (see section 3), it was determined that these two cases (LS95b) occurred during a high- (low-) amplitude Northern Hemispheric planetary-scale flow regime, or mode 2 (mode 1 ) as stated by Hansen (1986). Thus, the differences in the relative importance of vorticity and temperature advection between these and the LS95b blocking events may be associated with the flow regime under which they occurred. Looking further, the scale partitioned results demonstrate that the $S$ component, often supported by $I$, was the primary contributor to height rises when upstream cyclones were interacting with the block (i.e., Figs. 2c, 4c, 5c and 10c), suggesting a more direct contribution in these (mode-2) cases. This contrasts with the results of LS95b (mode 1 case) that demonstrated that the $I$ component was the largest contributor to the height rises associated with block formation, suggesting a more indirect role for the cyclones during block interactions. These results are also consistent with the observation that regional partitioned height tendencies for these two cases were dominated by $S$ and $P$ (not shown), while in the case study of LS95b (see their Table 1), which occurred prior to the two blocks studied here, $I$ and $S$ were dominant. Finally, during decay, it was found that $S$ and $I$ height falls were prominent contributors to block decay for these (mode-2) cases as opposed to $P$ height falls playing the more prominent role in $\mathrm{LS} 95 \mathrm{~b}$, a mode 1 case. 

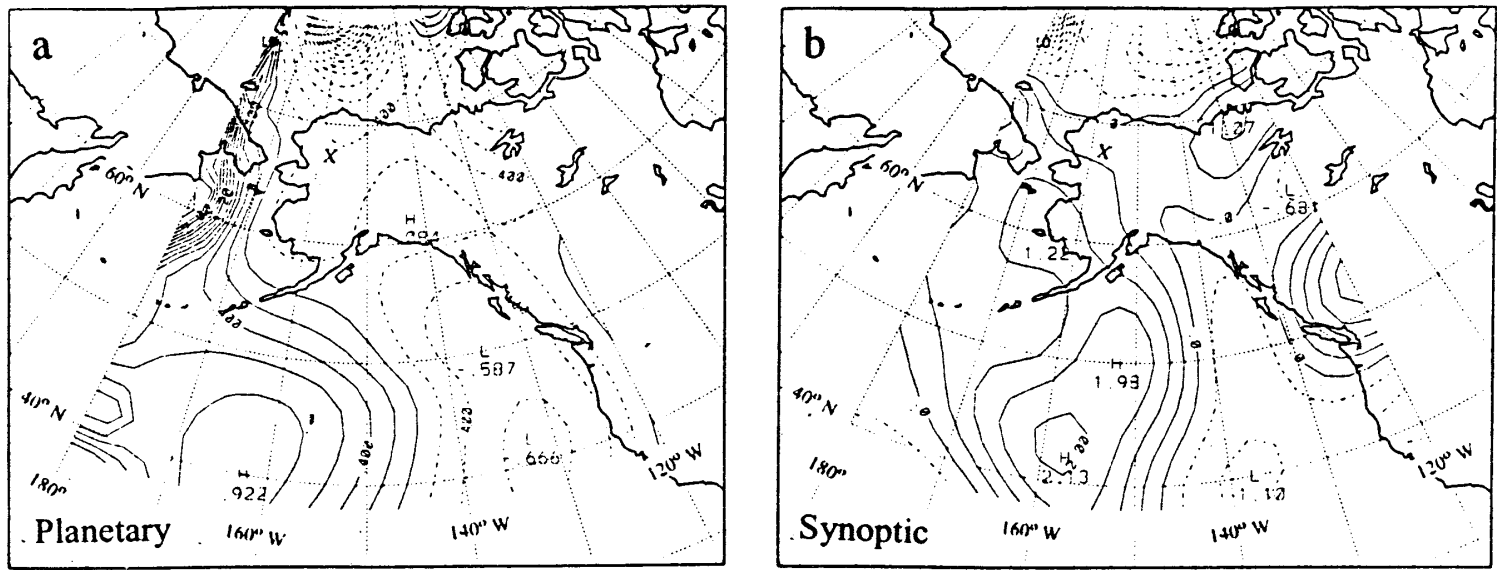

\section{UTC 22 November}

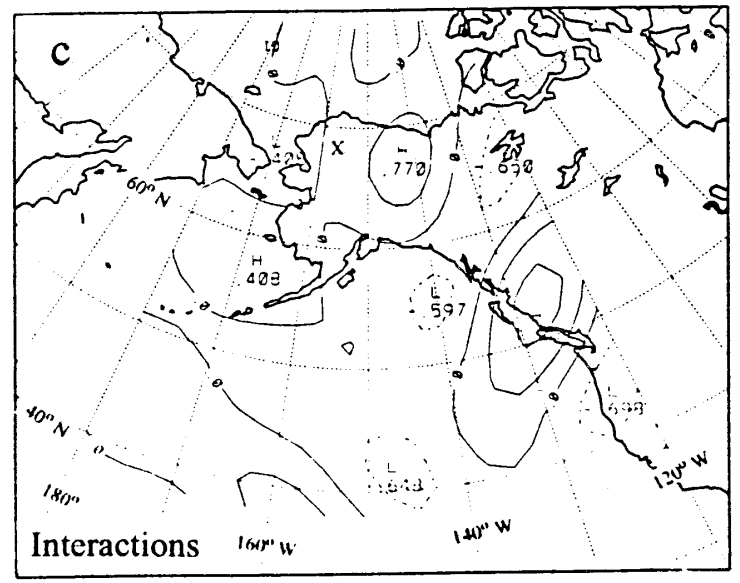

FIG. 16. As in Fig. 8 except for 0600 UTC 22 November 1985.

\section{Summary and conclusions}

The life cycles of two Northern Hemisphere blocking anticyclones that occurred simultaneously have been examined over their entire life cycle using the Z-O equation as the primary diagnostic tool. These blocking anticyclones were chosen from the set of 63 blocking anticyclones, described in the LS95a climatology, that occurred between 1 July 1985 and 30 June 1988. Unlike other case studies, these diagnoses examined the entire life cycle of each blocking event. This work focused on two objectives; the primary, to determine what connection, if any, there was between the simultaneously occurring blocks, and a secondary, to compare the relative importance of forcing mechanisms in the life cycles of these blocking anticyclones to those in LS95b.

The results of Austin (1980), Trenberth and Mo (1985), Quiroz (1987), or Lejenas and Madden (1992) could imply that there may be a connection between the occurrence of blocking in one region and the simultaneous existence or demise of blocking in another region. However, many studies, including Trenberth and Mo (1985) and this one, have argued that blocking is a local phenomenon. Using the techniques of these diagnoses, the results of section 6 demonstrate that there was no dynamic connection between the concurrent existence of the Pacific and Atlantic blocking events examined here. These results are in agreement with those of Lejenas and Okland (1983), who demonstrate using statistical methods that there is no connection between the simultaneous existence of blocking in different regions of the Northern Hemisphere. These results also suggest that blocking is a phenomenon that has a strong local influence, as exhibited by the importance of the synoptic-scale component to the total height tendencies dur- 

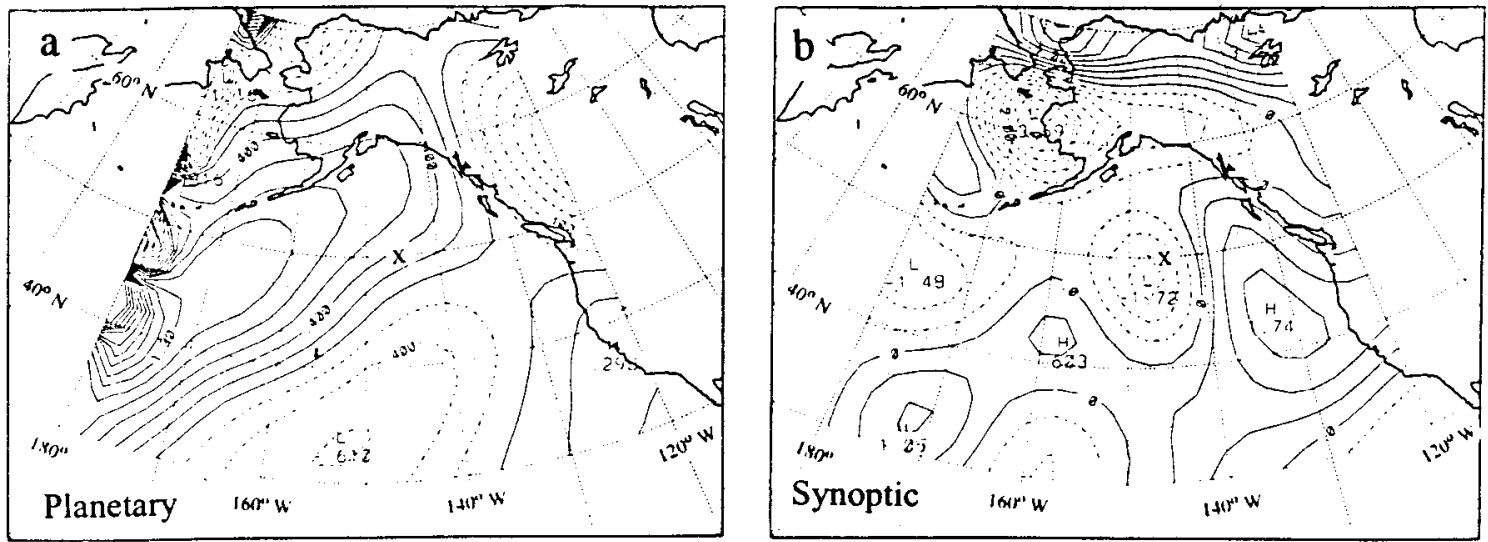

\section{UTC 25 November}

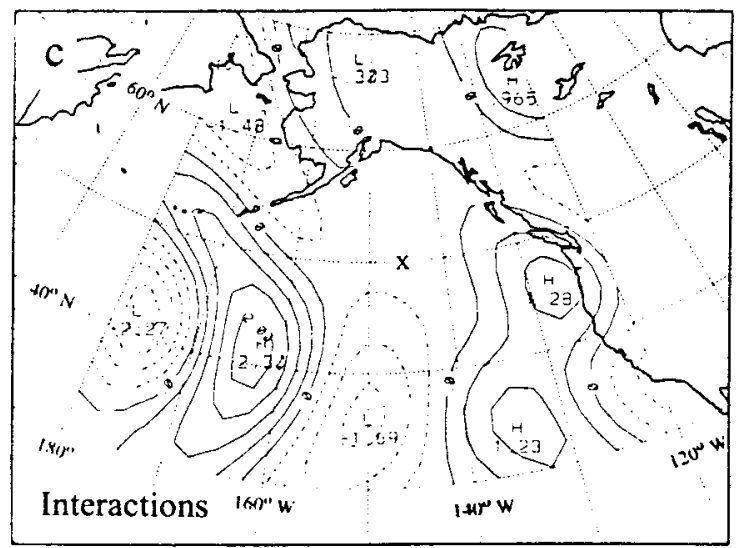

FIG. 17. As in Fig. 8 except for 1200 UTC 25 November 1985

ing various stages of the block life cycle, supporting the conclusions of Trenberth and Mo (1985) and others. These conclusions were also reached by earlier modeling studies, such as Kalnay-Rivas and Merkine (1981) and Shutts (1983), who both showed that blocking is most likely the result of the superposition of favorable large- and synoptic-scale forcing.

Additionally, early modeling studies, such as Frederiksen (1982) and Shutts (1983), suggested that midlatitude transients played a crucial role in block formation and/or maintenance. Furthermore, there have been studies (e.g., Illari 1984 and Mullen 1987) that have shown observationally the ensemble effects of midlatitude transients in the maintenance of blocking anticyclones. Studies such as Tsou and Smith (1990) and LS95b demonstrate the dynamic connection between an individual cyclone and block onset. This study demonstrates a connection between individual midlatitude transients, especially extratropical cyclones, particularly in block formation and intensification. Section
4 shows that almost every cyclone discussed, and their development, just upstream of the block could be associated with block development or intensification (except for the decay of the Pacific case).

By comparing the results of this work with that of LS95b, there were some differences that could be associated with blocking events that occurred in low (mode 1) and high (mode 2) amplitude planetary-scale flow regimes. In particular, the composite height tendency results in section 5 showed that temperature advection was the most significant contributor to block formation for these two cases that occurred in a mode 2 flow regime. This contrasts with the LS95b case (mode 1) where AVA was the primary contributor to block formation. Also, the scale-partitioned results suggest that the cyclones contributed to block formation and maintenance directly in mode 2 cases through the $S$ component. This contrasts with the results of LS95b, which demonstrated that the I component was the largest contributor to the height rises associated with block formation, suggesting a more 
indirect role for the cyclones in block interactions. Finally, during decay, it was found that $S$ and $I$ height falls were prominent contributors to block decay for mode 2 cases as opposed to $P$ height falls playing the more prominent role in a mode 1 case (LS95b).

Acknowledgments. The author would like to thank Dr. Phillip J. Smith for his comments and suggestions in reviewing this work, and the two anonymous reviewers whose comments were very helpful. This work was partially supported by the National Aeronautics and Space Administration through NASA Grant NAG8-915.

\section{REFERENCES}

Alberta, T. L., S. J. Colucci, and J. C. Davenport, 1991: Rapid 500-mb cyclogenesis and anticyclogenesis. Mon. Wea. Rev., 119, 11861204.

Austin, J. F., 1980: The blocking of middle latitude westerly winds by planetary waves. Quart. J. Roy. Meteor. Soc., 106, 327-350.

Baker, W. E., S. C. Bloom, J. S. Wollen, M. S. Nestler, E. Brin, T W. Schlatter, and G. W. Branstator, 1987: Experiments with a three-dimensional statistical objective analysis scheme using FGGE data. Mon. Wea. Rev., 115, 272-296.

Blackmon, M. L., J. M. Wallace, N.-C. Lau, and S. L. Mullen, 1977: An observational study of the Northern Hemisphere winter circulation. J. Atmos. Sci., 34, 1040-1053.

Charney, J. G., and J. G. DeVore, 1979: Multiple flow equilibria in the atmosphere and blocking. J. Atmos. Sci., 36, 1205-1216.

Colucci, S. J., 1985: Explosive cyclogenesis and large-scale circulation changes: Implications for atmospheric blocking. J. Atmos. Sci., 42, 2701-2717.

- 1987: Comparative diagnosis of blocking versus non-blocking planetary circulation changes during synoptic scale cyclogenesis. J. Atmos. Sci., 44, 124-139.

— A. Z. Loesch, and L. F. Bosart, 1981: Spectral evolution of a blocking episode and comparison with wave interaction theory. J. Atmos. Sci., 38, 2092-2111.

Dole, R. M., 1986: The life cycles of persistent anomalies and blocking over the North Pacific. Advances in Geophysics, Vol. 29, Academic Press, 31-70.

Egger, J., W. Metz, and G. Muller, 1986: Forcing of planetary-scale blocking anticyclone by synoptic-scale cyclones. Advances in Geophysics, Vol. 29, Academic Press, 183-198.

Fosdick, E. K., and P. J. Smith, 1991: Latent heat release in an extratropical cyclone that developed explosively over the southeastern United States. Mon. Wea. Rev., 119, 193-207.

Frederiksen, J. S., 1982: A unified three-dimensional instability theory of the onset of blocking and cyclogenesis. J. Atmos. Sci., 39, 969-982.

Haltiner, G. J., and R. T. Williams, 1980: Numerical Prediction and Dynamic Meteorology. John Wiley \& Sons, 478 pp.

Hansen, A. R., 1986: Observational characteristics of atmospheric planetary waves with bimodal amplitude distributions. Advances in Geophysics, Vol. 29, Academic Press, 101-134.

Harshvardhan, R. Davies, D. A. Randall, and T. G. Corsetti, 1987: A fast radiation parameterization for atmospheric circulation models. J. Geophys. Res., 92, 1009-1016.

Illari, L., 1984: A diagnostic study of the potential vorticity in a warm blocking anticyclone. J. Atmos. Sci., 41, 3518-3525.

Kalnay-Rivas, E., and L.-O. Merkine, 1981: A simple mechanism for blocking. J. Atmos. Sci., 38, 2077-2091.

Konrad, C. E., and S. J. Colucci, 1988: Synoptic climatology of 500-mb circulation changes during explosive cyclogenesis. Mon. Wea. Rev., 116, 1431-1443.

Krishnamurti, T. N., 1968: A diagnostic balance model for studies of weather systems of low and high latitudes, Rossby numbers less than one. Mon. Wea. Rev., 96, 518-530.

Kuo, H. L., 1974: Further studies of the parameterization of the influence of cumulus convection on large-scale flow. J. Atmos. Sci., 31, 1232-1240.

Lejenas, H., and H. Okland, 1983: Characteristics of Northern Hemisphere blocking as determined from a long time series of observational data. Tellus, 35A, 350-362.

— blocking. Mon. Wea. Rev., 120, 2821-2830.

Lupo, A. R., and P. J. Smith, 1995a: Climatological features of blocking anticyclones in the Northern Hemisphere. Tellus, 47A, 439-456.

— , and P. J. Smith, 1995b: Planetary and synoptic-scale interactions during the life cycle of a mid-latitude blocking anticyclone over the North Atlantic. Tellus, 47A, 575-596.

—, P. J. Smith, and P. Zwack, 1992: A diagnosis of the explosive development of two extratropical cyclones. Mon. Wea. Rev., 120, $1490-1523$.

Mak, M., 1991: Dynamics of an atmospheric blocking as deduced from its local energetics. Quart. J. Roy. Meteor. Soc., 117, 477493.

Mullen, S. L., 1987: Transient eddy forcing and blocking flows. $J$. Atmos. Sci., 44, 3-22.

Quiroz, R. S., 1987: Travelling waves and regional transfers in blocking action in the Northern Hemisphere. Mon. Wea. Rev., 115, 919-935.

Rausch, R. L. M., and P. J. Smith, 1996: A diagnosis of a modelsimulated explosively developing extratropical cyclone. Mon. Wea. Rev., 124, 875-904.

Rex, D. F., 1950: Blocking action in the middle troposphere and its effect upon regional climate II. The climatology of blocking action. Tellus, 2, 275-301.

Rolfson, D. M., and P. J. Smith, 1996: A composite diagnosis of synoptic-scale extratropical cyclone development over the United States. Mon. Wea. Rev., 124, 1084-1099.

Sasamori, T., 1968: The radiative cooling calculation for application to general circulation experiments. J. Appl. Meteor., 7, 721-729.

Schubert, S. D., R. D. Rood, and J. Pfaendtner, 1993: An assimilated dataset for earth science applications. Bull. Amer. Meteor. Soc., 74, 2331-2342.

Shapiro, R., 1970: Smoothing, filtering, and boundary effects. Rev. Geophys., 8, 359-387.

Shutts, G. J., 1983: The propagation of eddies in diffluent jet streams: Eddy vorticity forcings of blocking flow fields. Quart. J. Roy. Meteor. Soc., 109, 737-761.

— 1986: A case study of eddy forcing during an Atlantic blocking episode. Advances in Geophysics, Vol. 29, Academic Press, 135161.

Sperenza, A., 1986: Deterministic and statistical properties of Northern Hemisphere middle latitude circulation. Advances in Geophysics, Vol. 29, Academic Press, 199-226.

Sutera, A., 1986: Probability density distribution of large-scale atmospheric flow. Advances in Geophysics, Vol. 29, Academic Press, 227-250.

Tracton, M. S., 1990: Predictability and its relationship to scale interaction processes in blocking. Mon. Wea. Rev., 118, 16661695.

Trenberth, K. E., and K. C. Mo, 1985: Blocking in the Southern Hemisphere. Mon. Wea. Rev., 113, 3-21.

- , and S.-C. Chen, 1988: Rotational and divergent geopotential components. J. Atmos. Sci., 45, 2949-2960.

Tsou, C.-H., and P. J. Smith, 1990: The role of synoptic/planetaryscale interactions during the development of a blocking anticyclone. Tellus, 42A, 174-193.

Tung, K. K., and R. S. Lindzen, 1979a: A theory of stationary long waves. Part I: A simple theory of blocking. Mon. Wea. Rev., 107, 714-734.

_, and 1 1979b: A theory of stationary long waves. Part II: Resonant Rossby waves in the presence of realistic vertical shear. Mon. Wea. Rev., 107, 735-750.

Zwack, P., and B. Okossi, 1986: A new method for solving the quasigeostrophic omega equation by incorporating surface pressure tendency data. Mon. Wea. Rev., 114, 655-666. 